\title{
THE CONTRIBUTION OF CHINESE DIASPORA RESEARCHERS TO GLOBAL SCIENCE AND CHINA'S CATCHING UP IN SCIENTIFIC RESEARCH
}

\author{
Qingnan Xie \\ Richard B. Freeman \\ Working Paper 27169 \\ http://www.nber.org/papers/w27169 \\ NATIONAL BUREAU OF ECONOMIC RESEARCH \\ 1050 Massachusetts Avenue \\ Cambridge, MA 02138 \\ May 2020, Revised February 2021
}

Previously circulated as "The Contribution of Chinese Diaspora Researchers to Scientific Publications and China's 'Great Leap Forward' in Global Science." We gratefully thank Dr Xi Hu from University of Oxford for her support in collecting data from Scopus. Qingnan Xie is supported by the National Social Science of China [16ZDA224]. The views expressed herein are those of the authors and do not necessarily reflect the views of the National Bureau of Economic Research.

NBER working papers are circulated for discussion and comment purposes. They have not been peer-reviewed or been subject to the review by the NBER Board of Directors that accompanies official NBER publications.

(C) 2020 by Qingnan Xie and Richard B. Freeman. All rights reserved. Short sections of text, not to exceed two paragraphs, may be quoted without explicit permission provided that full credit, including $\odot$ notice, is given to the source. 
The Contribution of Chinese Diaspora Researchers to Global Science and China's Catching Up in Scientific Research

Qingnan Xie and Richard B. Freeman

NBER Working Paper No. 27169

May 2020, Revised February 2021

JEL No. F1,I2,J2,J3,J5,O3

\begin{abstract}
$\underline{\text { ABSTRACT }}$
This study examines the contribution of Chinese diaspora researchers - those born in China but working outside the country - to China's catching up in global science to become a world leader in research publications and citations. Using a novel name-based way to identify Chinese diaspora authors of scientific papers, we show that these researchers produce a large proportion of global scientific papers of high quality, gaining about twice as many citations as other papers of the same vintage. Our analysis also shows that diaspora researchers are a critical node in the coauthorship and citation networks that connect scientific discovery in China with the rest of the world. In co-authorship, diaspora researchers are over-represented on international collaborations with China-addressed authors. In citations, a paper with a diaspora author is more likely to cite China-addressed papers than a non-China addressed paper without a diaspora author; and, commensurately, China-addressed papers are more likely to cite a non-China addressed paper with a diaspora author than a non-China paper without a diaspora author. Through those pathways, diaspora research contributed to China's 2000-2015 catch-up in science and to global science writ large, consistent with ethnic network models of knowledge transfer, and contrary to brain drain fears that the emigration of researchers harms the source country.
\end{abstract}

Qingnan Xie

Nanjing University of Science and Technology

200 Xiaolingwei Street

Xuanwu District, Nanjing, Jiangsu 210094

China

2362626753@qq.com

Richard B. Freeman

NBER

1050 Massachusetts Avenue

Cambridge, MA 02138

freeman@nber.org 


\section{Introduction}

In the latter part of the $20^{\text {th }}$ century and early decades of the $21^{\text {st }}$ century China advanced from the periphery of the global economy, accounting for barely $2 \%$ of world GDP and $1 \%$ of world trade in the early 1970s, to second largest economy with about 17\% of world GDP in 2019 and $12.4 \%$ of world trade in $2018^{1}$. China made a similarly impressive catch-up in science and engineering. It increased R\&D spending from modest amounts in 2000 to exceed EU spending in purchasing power parity terms and to approach US levels of R\&D spending by the late 2010s. In 2018 the Scopus database of academic research papers ${ }^{2}$ ranked China first in number of publications and second to the US in citations. Combining improved research capability with manufacturing prowess, China further advanced in high research-intensive industries (Xie and Freeman, 2019).

Few analysts anticipated China's gaining comparative advantage in science and engineering research so rapidly. Comparative advantage in research depends on developing a world class higher education system, spending a sizable share of GDP on R\&D, and implementing effective national science, technology, and innovation policies (Chen et al., 2020), all of which traditionally occurs late in the development process. When Deng Xiaoping initiated economic reforms following the 1966-76 Cultural Revolution, China's higher education and research system were at rock bottom. From the late 1970s through the 1990s China expanded enrollment in existing institutions of higher education and developed new colleges and universities to educate millions of bachelor's degree holders and greatly increase master's and PhDs students and graduates, mostly in STEM fields. But the country did not have the scientific expertise to play more than a minor role in global scientific research nor in high tech manufacturing and service sectors. Recognizing that linking Chinese research more closely to global science would help the country catch-up in science and technology, China's government encouraged some of its best and brightest students and researchers to go overseas for education and work, and maintained and expanded such policies after the Tianamen Incident, accepting the risk that some might not return (Chen, 2009; Miao et al., 2009).

\footnotetext{
${ }^{1}$ These studies assess the costs of the brain drain to the source country and often seek ways to recompense the lowincome source country for their loss or to subsidize home-grown researchers (Docquier, Lohest and Marfouk, 2007; Cao, 2008; Ziguras and Gribble, 2015).

${ }^{2}$ Scopus is the largest bibliometry of scientific journals with wide coverage of China-published English and Chinese language journals. English is the primary language of science and the language for 88\% of Scopus journal articles. The 350 active Chinese language journals in Scopus make Chinese the 2nd largest language, accounting for $4.8 \%$ of 2018 articles.
} 
To examine the contribution of the diaspora researchers of our title - those born in China who conducted their research at non-China addresses - to global science and to China's catch-up in science, we developed a novel name-based method for identifying them when they work overseas. Using our name-based measures of diaspora research, we adjust the conventional address-based measure of a country's contribution to scientific publication for papers written by diaspora researchers by dividing credit between China and the country address on the paper. The diaspora share of world papers is sufficiently large that our adjustment adds noticeably to China's contribution. We further examine the impact of diaspora researchers on the publication of collaborative papers with China-addressed researchers. To estimate the effect of diaspora papers on the network of citations, we measure the citations that China-addressed papers received from diaspora papers and the citations that they give to diaspora work compared to papers without diaspora authors.

Since diaspora researchers are migrants, our paper contributes to analyses of the effect of high skilled immigrants on source and destination economies in general. There are two competing views in this area of research. Traditional brain drain literature views emigration as a loss that weakens the ability of the source country to upgrade its productive capacity and thus slows their catch-up with economically advanced countries (Docquier and Rapoport, 2012). Analysis of the immigration of scientific workers to high income countries stress that immigrants expand the supply of S\&E workers and produce exceptionally high quality work. In the case of the US, Science and Engineering Indicators 2020 reports that the foreign born made up about one-third of S\&E researchers in US academia and about half of post-docs in 2017. Stephan and Levin (2001) document the exceptional contribution of immigrants to US academic papers and patents - which our analysis confirms for papers by Chinese diaspora researchers in 2000-2018. The "ethnic network view" offers a different perspective of what S\&E migrants do for their source and destination countries due to their having social network links to persons in both countries. It treats highly skilled migrants as a positive channel of communication and knowledge that allows the source country to access advancesin science and technology more rapidly than would otherwise be possible (Kerr, 2008), turning "the old dynamic of 'brain drain' ... to ... 'brain circulation'” (Saxenian, 2002). Research on ethnic networks finds trade links between the country of emigration and the country of immigration (Saxenian and Hsu, 2001; Felbermayr et al., 2010; Aleksynska and Peri, 2014; Behncke, 2014), and greater diffusion of technology from origin to destination countries and from destination to origin countries 
(Lissoni, 2018), with effects that differ between the most innovative and average innovations (Agrawal, Kapur, McHale and Oettl, 2011). Studies of scientific publications document that papers tend to "overcite“ papers with the same country address as the papers' authors (Glänzel and Schubert, 2005; Bakare and Lewison, 2017) and that international collaborations obtain more citations than otherwise similar papers with only one country address (Katz and Hicks,1997). Tracing the use of unique references and technical terms in the abstract of papers, Aman (2020) shows that co-authorship spreads knowledge among authors across countries. Absent a simple way to identify diaspora researchers in the data, however, none of these studies examines the effect of an ethnic network linking diaspora researchers to their home country on the flow of knowledge. Czaika and Orazbayev (2018), and Robinson-Garcia et al (2019) study researcher mobility through changes of affiliation addresses on papers without capturing the researchers' diaspora status nor identifying the large number of immobile diaspora researchers in a given locale. Our name-based methodology fills this gap, allowing us to identify the population of diaspora researchers and assess their contribution to global science and China's catch-up in scientific publications.

The rest of the paper contains five sections. Section 2 describes the methodology we use to identify Chinese diaspora researchers and the hypotheses that we examine in assessing their role in China's catch-up. Section 3 estimates the number of diaspora papers, their quality as reflected in citations and the journals that publish them, and their contribution to China's catch-up in world papers and citations. Section 4 examines the role of diaspora researchers on collaborative papers between China and the rest-of-the-world. Section 5 measures the extent to which diaspora papers 'overcite' China-addressed papers and the extent to which China-addressed papers 'overcite' diaspora papers. The final section concludes.

\section{Methodology and Hypotheses}

\subsection{Methodology of Identifying Chinese Diaspora Researchers}

Building on the work of researchers who use differences in the frequency of names among groups to identify the most likely ethnicity or nationality of persons (Ambekar et al., 2009; Freeman and Huang, 2015; Ye et al., 2017; Alshebli et al., 2018), we developed a two stage method to find Chinese diaspora authors in the Scopus database. In the first stage, we determine an author's Chinese ethnicity by whether their last name is in the Chinese Ministry of Public 
Security's list of most common Chinese last names ${ }^{3}$. Names on this list cover $84.8 \%$ of the mainland population. In the second stage we differentiate someone born in mainland China from someone born in some other location by identifying whether the person's first name follows the grammar of the Hanyu Pinyin translation system used in mainland China. Since mainland born Chinese almost invariably have Chinese first names as well as family names - Xixi, Wei, and Fang - while those born outside China are likely to have a first name that fits their country Sharon, David, Anne -- first names help differentiate persons in the two groups. Our scheme labels You Wang as China born and John Wang as non-mainland China born. The different structures of the syllables of pinyin in mainland China and other Chinese language speaking areas further differentiates mainland names from other Chinese language area names ${ }^{4}$. For example, "Xie” is the mainland pinyin translation of “谢”, which is translated as “Tes” in Hong Kong, and "Hsieh" in Taiwan.

Based on names, we define a Chinese diaspora (D) author as an author with first and last Chinese names writing an academic paper with an address outside China. We define a Chinese diaspora paper as a paper with one or more such authors. Thus, a paper by Qing Yang at a US address would be a diaspora paper and Qing Yang would be a diaspora author. By contrast, author David Yang at a US address would not qualify as diaspora and his paper would count as a US paper while Qing Yang writing at a Chinese address would be a Chinese-born author writing a Chinese paper. We label papers with all non-China addresses and one or more diaspora authors as a nonChina diaspora (NCD) paper.

Our method is well-suited for identifying researchers from source countries whose names differ sharply from the names in the destination country but would fail for persons working in a foreign country where their name is frequent among natives ${ }^{5}$. Given that the mapping between names on the list of common names and birth in China is not bijective our method will produce some errors in identifying diaspora researchers. It will understate the number of diaspora authors when a Chinese-born author working overseas changes their name to a non-Chinese name or has a rare Chinese name not on the Ministry of Public Security list. It will overstate the number of

\footnotetext{
${ }^{3}$ See the list of most common Chinese last names at: https://www.mps.gov.cn/n2254314/n6409334/c6874817/content.html.

${ }^{4}$ The program distinguishing Chinese first names is available at GitHub: https://github.com/qingnanxie/Chinesefirst-name.

${ }^{5}$ For many groups, names do not identify country of origin. For instance, John O'Leary with a US address could be an Irish immigrant or a US born Irish-American while Ingrid Swenson could be a Swedish immigrant or US born Swedish-American.
} 
diaspora authors by counting as Chinese-born an ethnic Chinese person born outside China whose parents gave them a Chinese first name. Given the large number of China-born researchers overseas who use their Chinese name, these errors are likely to be modest. As a check on our name-based identification of authors as coming from mainland China, we examined what authors that we identified as Chinese born from their first and last names reported about themselves on the ORCID ${ }^{6}$ database. Using the author's Scopus ID we matched 259 researchers from our sample of 2018 diaspora researchers to their ORCID records. Given that ORCID does not have data on place of birth we used the matched researchers report of where they obtained their bachelor's degree as an indicator of likely place of birth, on the hypothesis that researchers with first and last mainland Chinese names graduating from a mainland institution have a high probability of being born in China. Of the 43 matches who reported the institution of their bachelor's degree on ORCID, 93\% (40 authors) reported an undergraduate degree from a mainland institution and one of the other three reported a Hong Kong undergraduate degree ${ }^{7}$. We further checked the undergraduate education and place of birth of the top material scientists identified as diaspora in Table 4 and found that all had undergraduate education in China, and were China-born by online retrieved CVs.

\subsection{Measures of the Quantity and Quality of Diaspora Papers}

Bibliometric studies that credit countries for scientific publications use the addresses of authors to allocate credit. A paper with all France-addressed authors is counted as a French paper. An all China-addressed paper is counted as a China paper. Credit on a paper with one author in one country and a second author in a different country is divided as $1 / 2$ to each. In Nauthored papers this fractional counting credits a country with $\mathrm{n}$ authors having that country's address with $\mathrm{n} / \mathrm{Nth}$ of the paper8. In situations in which one author has 2 or more country addresses, the natural division is to divide that authors' share of credit proportionately among those countries. For example, a three-authored paper in which one author has a China address, one has a US address, and the third has a China and a France address, the 1/3rd credit of the third

\footnotetext{
${ }^{6}$ ORCID provides an identity for researchers that distinguish a particular author's contributions to the scientific literature as most personal names are not unique, they can change (such as with marriage), have cultural differences in name order, and other variations. More details: https://en.wikipedia.org/wiki/ORCID and https://info.orcid.org/what-is-orcid/.

${ }^{7}$ The small sample results from Chinese researchers being under-represented on ORCID (Bohannon and Doran, 2017) and the absence of CV type information fir many ORCID authors (Conchi and Michels, 2014).

8“Fractional counts of articles are those produced by authors from different countries, where each country receives fractional credit on the basis of the proportion of its participating authors.” See note in Appendix of SEI 2020, TABLE S5A-2.
} 
author would be split between France and China, so that credit for the whole paper would go 1/3rd to the US, 1/2 to China, and 1/6th to France.

Extending fractional crediting to diaspora papers, we count a non-China addressed paper with $\mathrm{n}$ of its $\mathrm{N}$ authors having Chinese first and second names that meet our criterion for likely birth on the mainland as being $\mathrm{n} / \mathrm{Nth}$ diaspora. A three authored non-China addressed paper with one author with Chinese names would be 1/3rd diaspora; a three-authored paper with two diaspora authors would be 2/3rds diaspora and one with all three authors having the appropriate Chinese names would be a full diaspora paper.

An increasing share of global papers are international collaborations among researchers in different countries, including diaspora authors. We label papers written by researchers in China and researchers outside China as China Joint papers (CJ); and papers with one or more Chinese named author at a non-China address as China Joint diaspora (CJD) papers. The diaspora share of a CJD paper is the ratio of the number of diaspora authors to all authors, including those with China addresses. The total number of diaspora papers is the sum of NCD and CJD papers.

\section{Citations and CiteScores}

We follow standard practice in using the number of forward citations that a paper receives from future publications as our main indicator of the impact/quality of a paper. We chose a 3 year forward citations as our citation measure and thus focus citation analysis on papers published through 2015. The 3-year period provides a reasonable indicator of the likely position of papers in citation distributions in succeeding years in the Scopus data set ${ }^{9}$. We also examined the CiteScore of the journal of publication that Scopus reports in its data base. The CiteScore is the number of total citations to the journal divided by the number of articles over the past four years ${ }^{10}$ and thus reflects the attention given to articles in the journal. Because high CiteScore journals attract many submissions, papers face a high acceptance hurdle for publication and are thus likely to be of high quality.

\footnotetext{
${ }^{9}$ Citation measures varies with the window of measurement, as citations increase over time (Abramo et al., 2011; Wang, 2013). Three year forward citation in a sample of 5989 papers published in 2000 had correlations of 0.97 with 5 year citations, 0.89 , with 7 year citations and 0.68 with 10 year citations. An extensive literature examines ways to predict later citations from early citations and other attributes of papers (Bornmann et al., 2014; Abrishami and Aliakbary, 2019).

${ }^{10}$ By contrast, the Web of Science computes its Impact Factor statistic (ratio of citations to articles over the past two years while Scimago uses the ratio of citations to articles over the past three years in the Scopus data base to calculate its own journal ranking.
} 
Citations and CiteScores are highly correlated11 but reflect different evaluation processes by different decision-makers that justifies analyzing both. The authors of future papers decide whether or not to cite a published article based on the influence the article had on their thinking or work, and also on their connection \to the authors, as evinced in homophily in citations (Bornmann and Daniel, 2008; Ghiasi et al., 2018). The reviewers and editors who consider publishing an article in a given journal presumably base their decisions on expectations of the article's validity and possible future importance, which presumably makes their assessment dependent on perceived quality rather than the size of a researchers' network.12 Analyzing results with both measures provides an independent replication or robustness test of findings and can identify differences in assessment worthy of study.

\section{Name-based crediting measures}

As noted, conventional analysis of crediting papers to countries is based solely on the address of authors. Allocating the credit of diaspora authors to their origin country as well as to the country in which they did their research allows us to give China some credit for diaspora research. We extend the fractional crediting countries by addresses to the names of authors by dividing credit equally to the authors' name and address so that $1 / 2$ of the credit for a Chinese diaspora author would go to China on the basis of their name and $1 / 2$ would go to their non-China address. On a paper with $\mathrm{n}$ diaspora authors and $\mathrm{N}$ total authors our scheme credits China with $(1 / 2)(n / N)$ of the paper and credits the rest to non-China.

Dividing credit between names and addresses equally is an approximation to the contribution that the author made on the basis of their' country of birth and place of work (Xie and Freeman, 2019) just as the standard addressed base division of credit among countries proportionate to their share of authors is an approximation to what the authors did. With additional information on the authors and their work, one could make more refined calculations, for instance giving a higher weight to China for diaspora researchers educated primarily in China compared to a diaspora researcher primarily educated overseas or giving higher weight for a diaspora researcher funded by Chinese sources rather than for one funded by non-Chinese sources, etc.

\footnotetext{
${ }^{11}$ We obtained a 0.5 correlation between three year forward citations and cite scores in a sample of 5,540 papers published in 2015 with valid cite scores. The correlation fits with Larivière et al. (2016)'s data on within-journal variation in citations.

${ }^{12}$ Lariviere and Sugimoto, (2019) provide a comprehensive discussion of impact factors and CiteScores.
} 


\subsection{Hypotheses}

Our analysis measures the Chinese diaspora contribution to global science and to China's rise in global publications and tests hypotheses about the role that diaspora papers had connecting Chinese and rest-of-the-world science. On the diaspora contribution, the selectivity of diaspora researchers suggests that they will perform above average in getting citations and high CiteScores for their papers, much as do immigrant scientists and engineers in general. On connecting China and rest-of-the-world science, the well-established phenomenon of homophily that produces concentrations of persons with similar characteristics in many forms of social behavior (McPherson, et al, 2001) leads us to expect diaspora researchers to be important in bringing China-based and rest-of-the-world science together. A diverse set of studies show that researchers coauthor extensively with people like themselves along many dimensions(Yan and Ding, 2012), ranging from geographic locale such as country (Schubert and Glänzel, 2006), ethnicity within the same country (Freeman and Huang, 2015), and gender (Wang, et al 2019, Boschini and Sjögren, 2007; AlShebli et, al., 2018). Researchers also tend to cite people like themselves more than others (Ghiasi, et al., 2018), culminating in self citations (King, et al, 2015).

Assuming that diaspora researchers are especially connected/homophilous with researchers in China ${ }^{13}$ we expect:

(H1) Diaspora researchers to have a higher propensity to co-author papers with China-based researchers than other researchers outside China.

(H2) China-addressed researchers to cite diaspora papers more than non-diaspora papers with non-China addresses relative to the number of those papers in the scientific literature.

(H3) Diaspora researchers to cite China-based research more frequently than other researchers writing outside China.

If these hypotheses are validated in the data, our analysis that treats diaspora research as part of China's scientific activity and has an empirical basis.

\section{Diaspora papers}

\subsection{The number of diaspora papers}

To estimate the number of Chinese diaspora papers, we gathered Scopus data on 1.6 million English language articles in natural and physical sciences, including engineering and

\footnotetext{
${ }^{13}$ This assumption need not apply to all researchers who move from one country to another with their source country. Refugees who flee a country may, in particular, prefer little or no linkage to the country from which they fled.
} 
mathematics. Of those articles, $16.8 \%$ had all China addresses, and thus are not diaspora. We counted the number of papers with at least one Chinese last-named author among the $83.2 \%$ of papers with a non-China address. We then estimated the proportion of those China last-named authors who meet our first name diaspora criterion from a sample of such papers as described in Appendix A.

Figure 1 shows the results. The figure assigns papers by address to three groups: those with China only (CO) addresses, those with non-China only (NC) addresses: and those with joint China and non-China (CJ) addresses. It gives our count of papers with at least one Chinese lastnamed author in the NC and CJ groups and our estimate of the number of papers with diaspora authors. The estimates show that the largest number of diaspora papers come from NC addresses (9.5\% of all papers), which is over double the $4.3 \%$ coming from CJ papers. The $13.8 \%$ sum is our estimate of all papers with at least one China diaspora author. Comparing the CJD share of the global total to the CJ share shows that $69 \%(=4.3 \%$ / 6.2\%) of collaborations between Chinabased researchers and non-China based researchers involve a diaspora author, consistent with the hypothesis that diaspora authors have a special role connecting China-based researchers and researchers outside China in collaborative work.

\section{Figure 1. Numbers of Journal Articles by Address and Names of Authors and Numbers Relative to World papers, 2018.}

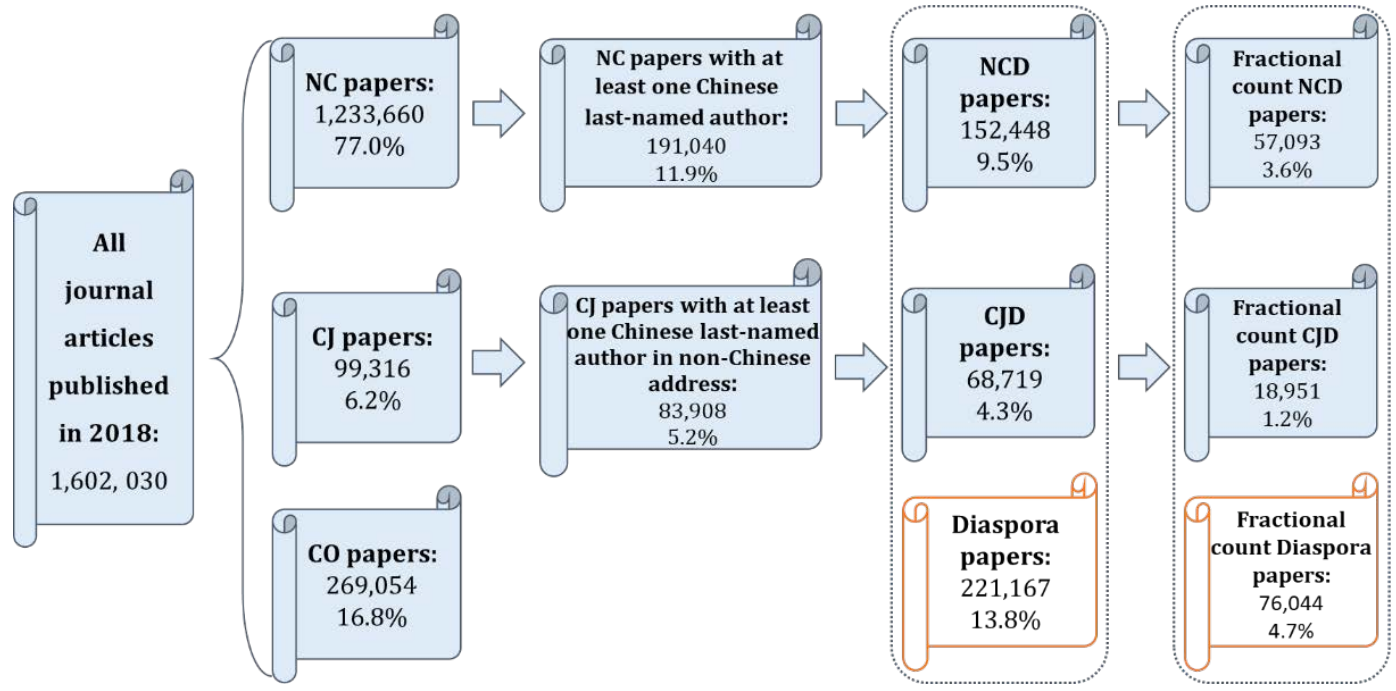

Note: Acronyms for the address-name papers CO: Papers with China Only addresses;

CJ: Papers with joint China and non-China addresses; NC: Papers with non-China only addresses; CJD: CJ papers with at least one Diaspora author; CJN: CJ papers with no Diaspora author; N CD: Papers with no Chinese address and with at least one Diaspora author; NCN: Papers with no Chinese addresses nor Diaspora author.

D author: Diaspora author; Author with Chinese first and last names and a non-Chinese address; NCN author: non-Chinese addressed and non-Chinese named author 
Source: Scopus English language journal articles in physical and natural sciences, including mathematics and engineering. This excludes papers in social sciences; arts and humanities; psychology; business, management and accounting; economics, econometrics and finance; decision sciences, and undefined. Appendix A describes the statistics and the sample of papers used to estimate the proportion of authors with Chinese first as well as last names.

Crediting diaspora research for an entire paper when diaspora researchers make up only part of the authorship arguably exaggerates the diaspora contribution. The statistics on the far right of Figure 1 show that fractional counting by the diaspora proportion of authors attributes $4.7 \%$ of 2018 papers to diaspora researchers ${ }^{14}$. This is far below the share of papers attributed to China or the US but is large relative to the standard addressed based attribution of world papers for almost all other countries. If diaspora researchers were from the country "Diaspora”, the 4.7\% proportion would place them fourth in world publications in 2018 behind only China, the US, and India by the fractional address measure ${ }^{15}$.

\subsection{Impact/quality of diaspora research}

To see how diaspora papers compare to other papers in the widely used citation measure of the impact or quality of research, Table 1 records three-year forward citations for 2015 papers differing in diaspora status. Given the heavy power-law tail of citations, in which many papers receive a few citations and a few receive many, the table gives the median of citations and the mean of the upper decile of the citation distribution as well as the mean. The statistics show that diaspora papers gained roughly twice the citations of NCN papers - those with non-Chinese addresses and no diaspora author - and roughly twice the citations of CO papers. The diaspora advantage is larger in mean citations than in median citations and is largest in the mean of the upper $10 \%$ of papers, indicative of the skew of the citation distribution. Measured by means, NCD papers lead all others but measured by medians, CJD papers top all others.

Table 1. Average 3 year forward citations of papers published in 2015

\begin{tabular}{|c|c|c|c|}
\hline \multicolumn{1}{|c|}{ Papers by address-name group } & Mean & Median & $\begin{array}{c}\text { Mean for top } \\
\text { decile of group }\end{array}$ \\
\hline $\begin{array}{l}\text { 1 NCD - NC (Non-China Only) papers with one or } \\
\text { more China named authors }\end{array}$ & $\mathbf{1 8 . 3}$ & $\mathbf{8 . 0}$ & $\mathbf{1 0 3 . 9}$ \\
\hline
\end{tabular}

\footnotetext{
${ }^{14}$ Following the methodology discussion, we prorated the address share of credit for an author with addresses in China and another country by giving $1 / 2$ to each of the two country addresses. In an n-authored paper, this gives $3 / 4 n$ to China and 1/4n to non-China. Because non-China named researchers with China addresses are a negligible part of China addressed papers, we ignored them but their contribution could be divided similarly by names and addresses.

${ }^{15}$ See National Science Board (2020) Table 5A-1, for fractional address counts of papers for China, the US, and India. In this calculation, we treat each diaspora author as a single country address. If we divide the diaspora fractional counts between the address of their affiliations and names, the diaspora number would drop by half to $2.4 \%$ and place the diaspora researchers in the $11^{\text {th }}$ place behind France.
} 


\begin{tabular}{|l|c|c|c|}
\hline 2 CJD - CJ papers with diaspora author (CJD) & $\mathbf{1 7 . 5}$ & $\mathbf{1 0 . 0}$ & $\mathbf{8 5 . 5}$ \\
\hline 3 CJN - CJ papers without diaspora author & 12.4 & 7.0 & 51.2 \\
\hline 4 CO - China Only addressed papers & 9.1 & 5.0 & 37.4 \\
\hline 5 NCN - NC papers with no China named author & 8.5 & 5.0 & 34.3 \\
\hline
\end{tabular}

Note: The standard errors for the means in citations are $0.3,0.7,1.0,0.9,2.1$, and 0.3 .

Source: All measures are based on 2,000 yearly CO, CJ and NC samples, see Appendix A for details.

Another way to assess the quality/impact of diaspora researchers is to examine their position on rankings of scientists by number of citations. In 2011 Clarivate Analytics published the "Top 100 Materials Scientists” based on 2000-2010 citations in its Web of Science data. Table 2 shows that five of the top 10 had Chinese first and last names and worked outside of China - diaspora authors. The five were employed by leading US universities. They all graduated from the University of Science and Technology of China, one of China's top universities with great strength in chemistry and materials science. They all graduated in the late 1980s-mid 1990s when few universities except those at the very top were likely to produce leading scientists. In the Clarivate list of the top 100 material scientists 12 were diaspora by our definition. 
Table 2. Top Ten Material Scientists, 2000-10, Ranked by Total Citations

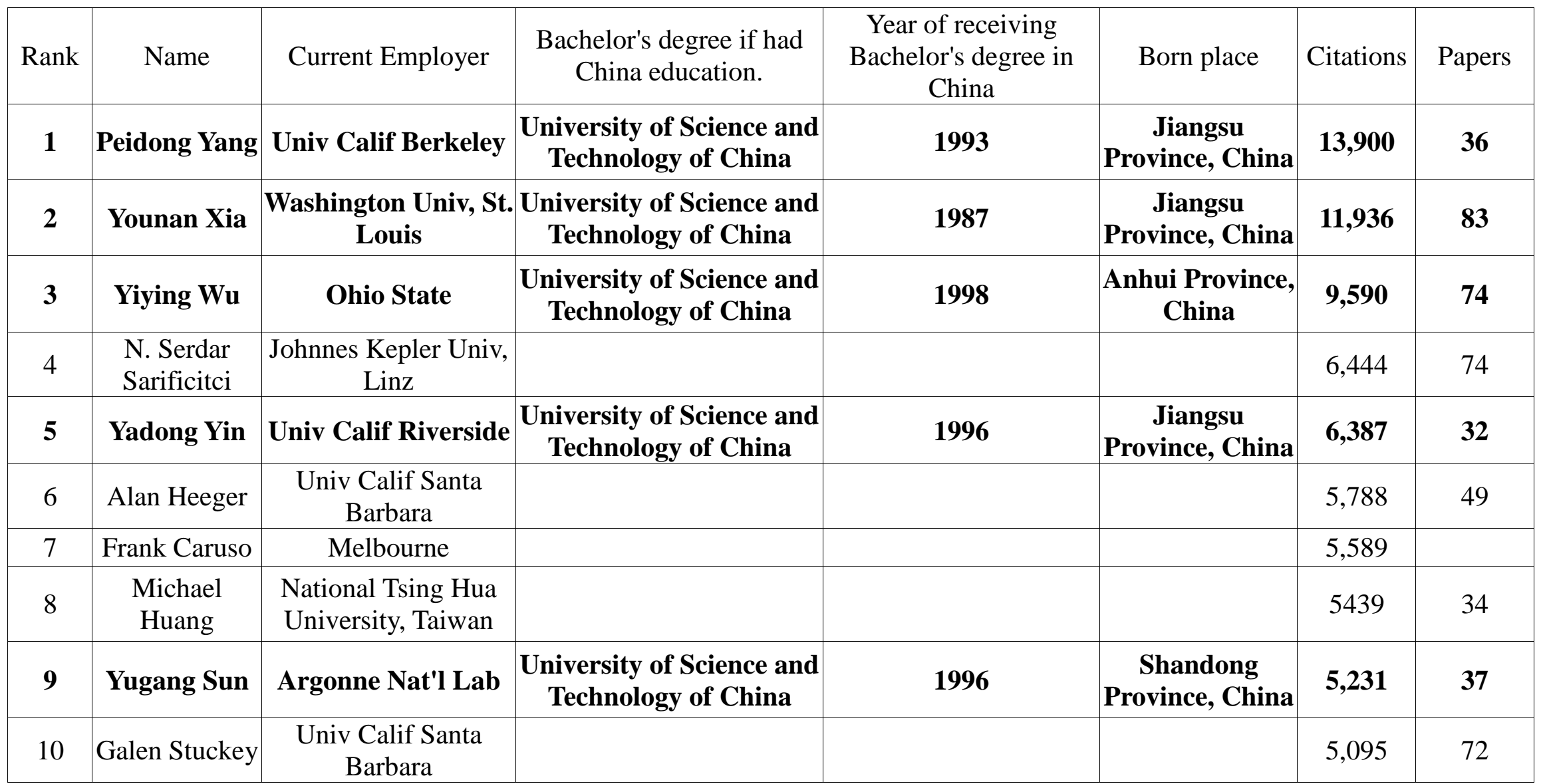

Note: Our ranking is based on total citations, whereas the Clarivate ranking is based on the ratio of citations to papers, which causes some differences between their statistics and ours. Diaspora researchers are in bold.

Source: Tabulated from Clarivate Science Watch, ‘Top 100 Materials Scientists’. http://archive.sciencewatch.com/dr/sci/misc/Top100MatSci2000-10/ 
As a check on the citation measure of quality/impact, Table 3 records the 2015 CiteScores of papers for different address-name groups ${ }^{16}$. Consistent with the citation data, the CiteScores show diaspora papers leading the list. The magnitude of the differences are smaller than in citations in part because the CiteScores average citations from many articles, concentrating the distribution of CiteScores more around its mean than the distribution of citations. Still, the diaspora advantage is high, with NCD papers having 1.5 times the mean CiteScore of NCN papers and 1.6 times the mean CiteScore of CO papers. As Scopus did not produce CiteScores until 2011 we limit ensuing analysis of China's catch-up in quality/impact of papers to citations.

Table 3. Average CiteScores of papers published in 2015

\begin{tabular}{|l|c|c|c|}
\hline \multicolumn{1}{|c|}{ Papers by address-name group } & Mean & Median & $\begin{array}{c}\text { Mean for top } \\
\text { decile of group }\end{array}$ \\
\hline $\begin{array}{l}\text { 1 NCD - NC Papers with one or more China named } \\
\text { authors }\end{array}$ & 4.7 & 3.5 & 13.0 \\
\hline 2 CJD - CJ papers with diaspora author (CJD) & 4.7 & 4.1 & 12.5 \\
\hline 3 CJN - CJ papers without diaspora author & 3.7 & 3.1 & 9.9 \\
\hline 4 CO - China Only addressed papers & 2.9 & 2.4 & 8.0 \\
\hline 5 NCN - NC papers with no China named author & 2.9 & 2.6 & 8.4 \\
\hline
\end{tabular}

Note: The standard errors for means of CiteScores are $0.1,0.1,0.1,0.2,0.2$, and 0.2 . The Cite Score values are assigned to papers based on the CiteScores of the journals in which they appeared. Scopus does not assign a CiteScores to new or inactive journals so observations on those journals are excluded at the CiteScore calculation.

Source: This calculation are based on the 2015 version of CiteScore measure issued by Scopus, downloaded at 25 May 2018.

Finally, we examined the quality of diaspora papers in terms of their getting into Nature and Science, arguably the top two general science journals, in 2000 and in 2018. Table 4 shows that in 2000 Nature and Science published virtually no papers with only China addresses and relatively few joint China-other country collaborative papers. The only Chinese born researchers with noticeable representation were diaspora researchers with NCD papers accounting for $16.4 \%$ of Nature papers and $18.1 \%$ of Science papers. Between 2000 and 2018, despite the seven-fold increase in the CO share of articles, the CO share of Nature

\footnotetext{
${ }^{16}$ As CiteScores are highly correlated over time, the results should be similar with modestly different year coverage. The correlation for the cite score of Scopus journals is 0.93 between 2017 and 2015, and is 0.87 between 2017 and 2011.
} 
and Science articles remained low. The big increase in China's presence in Nature and Science was in diaspora articles. In 2018 30.3\% of papers in Nature and 35.0\% in Science had a diaspora author. Calculating the fractional share of diaspora researchers on Science and Nature papers as if they were from 'Diaspora', gives a $10.4 \%$ proportion in Science that places them second behind the US and an $8.5 \%$ fractional proportion in Nature that places them third behind the US and $\mathrm{UK}^{17}$.

The diaspora advantage in citations and CiteScores could be due to differences in the attributes of papers and authors beyond addresses and names - for instance in field of study, number of authors, or other factors associated with citations or publication in high prestige journals (Börner et al., 2010; Abramo and D’Angelo, 2015). To see if our diaspora advantages hold up in the face of other determinants of citations and CiteScores we estimated a linear regression model linking the number of citations, the LN of citations, and CiteScores to dummy variables for the different address-name groups of papers and 21 dummy variables for the fields of papers identified in Scopus, and a continuous variable for the numbers of authors on a paper. The regression results in Appendix Table $\mathrm{C}$ show that the LN of citations better fits the citations data because of the power law distribution of the number of citations, and the inclusion of field dummies and numbers of authors greatly improves the fit of the equations but reduces the coefficients on NCD and CJD only modestly $^{18}$.

\footnotetext{
${ }^{17}$ This calculation we treats each diaspora author as a single country address rather than dividing it between the address of their affiliations and Chinese names.

${ }^{18}$ We explored four non-linear specifications as well: (1) a LN regression with one citation added to each observation to keep 0 citation papers in the regression; (2) a LN regression limited to positive citation observations with a separate equation that estimates the impact of factors on the probability of positive citations; and (3) a regression with citations and CiteScores scaled into a 0-1 interval by dividing each observation of a variable by its maximum value; and (4) a power law regression of the Ln of citations on the Ln rank of citations. These results are available as supplementary material from request on the authors.
} 
Table 4. Chinese Diaspora Papers in Nature and Science, 2000 and 2018

\begin{tabular}{|c|c|c|c|c|}
\hline & 2000 & 2018 & 2000 & 2018 \\
\hline & \multicolumn{2}{|c|}{ Nature } & \multicolumn{2}{|c|}{ Science } \\
\hline \multicolumn{5}{|c|}{ Panel A. Proportion of papers with presence of diaspora author } \\
\hline 1.Papers without Chinese address but with at least one China named authors (NCD) & $16.4 \%$ & $24.6 \%$ & $18.1 \%$ & $27.0 \%$ \\
\hline 2.China Joint papers with diaspora authors (CJD) & $0.2 \%$ & $5.7 \%$ & $0.2 \%$ & $8.0 \%$ \\
\hline 3.China Joint papers without diaspora authors (CJN) & $0.2 \%$ & $3.4 \%$ & $0.5 \%$ & $2.1 \%$ \\
\hline 4.Only China addressed papers (CO) & $0.3 \%$ & $0.9 \%$ & $0.2 \%$ & $2.6 \%$ \\
\hline 5.Non-China Addressed Papers with no China name author (NCN) & $82.8 \%$ & $65.3 \%$ & $80.9 \%$ & $60.3 \%$ \\
\hline \multicolumn{5}{|c|}{ Panel B. Proportion of papers by fractional counts of diaspora authors } \\
\hline Treating diaspora as separate country & & & & \\
\hline 1. Papers without Chinese address but with at least one China named authors (NCD) & $5.9 \%$ & $6.2 \%$ & $6.8 \%$ & $7.7 \%$ \\
\hline 2. China Joint papers with diaspora authors (CJD) & $0.1 \%$ & $2.3 \%$ & $0.2 \%$ & $2.7 \%$ \\
\hline 3. Diaspora papers $(N C D+C J D)$ & $6.0 \%$ & $8.5 \%$ & $7.0 \%$ & $10.4 \%$ \\
\hline \multicolumn{5}{|l|}{ Dividing the credit of diaspora author between their address and names } \\
\hline 4. Papers without Chinese address but with at least one China named authors (NCD) & $3.0 \%$ & $3.1 \%$ & $3.4 \%$ & $3.9 \%$ \\
\hline 5. China Joint papers with diaspora authors (CJD) & $0.1 \%$ & $1.2 \%$ & $0.1 \%$ & $1.4 \%$ \\
\hline 6. Diaspora papers $(N C D+C J D)$ & $3.0 \%$ & $4.3 \%$ & $3.5 \%$ & $5.2 \%$ \\
\hline
\end{tabular}

Note: Tabulated from every edition of Nature and Science in the specified year.

Source: Scopus database 


\subsection{Diaspora share of China's scientific publications}

Crediting part of the contribution of diaspora Chinese researchers to China's scientific publications shows that they were a huge pathway for China-born people to contribute to global science, particularly when the country was very poor and unable to fund much scientific work. The diaspora contribution was possible because researchers were willing and able to leave China, often with government support, and because other countries accepted them - indicative of the openness of the scientific world to migration.

Figure 2 organizes the data on diaspora papers to measure their quantitative importance in China's publications. The left side of the figure estimates China's presence in the scientific literature as the sum of papers with at least one Chinese name or address (CO, CJ, and NCD papers) irrespective of the proportion of addresses or names from China on the paper. Presence is a maximal measure of China's scientific activity. In 2018 China had a presence on 520,625 scientific papers, 42.4\% of which are diaspora papers. The right-hand side of the figure reports our minimal measure of China's scientific activity: the fractional count of all the address-name groups of papers dividing credit for diaspora authors evenly between China (for their name) and nonChina (for the foreign address). It gives China credit for 401,300 full papers and reduces the contribution of diaspora authors to $10.5 \%$ of the China's papers.

Figure 2. Journal Articles with China Addressed Authors or Chinese Named Authors by whole count and Address and Name based fractional count, 2018

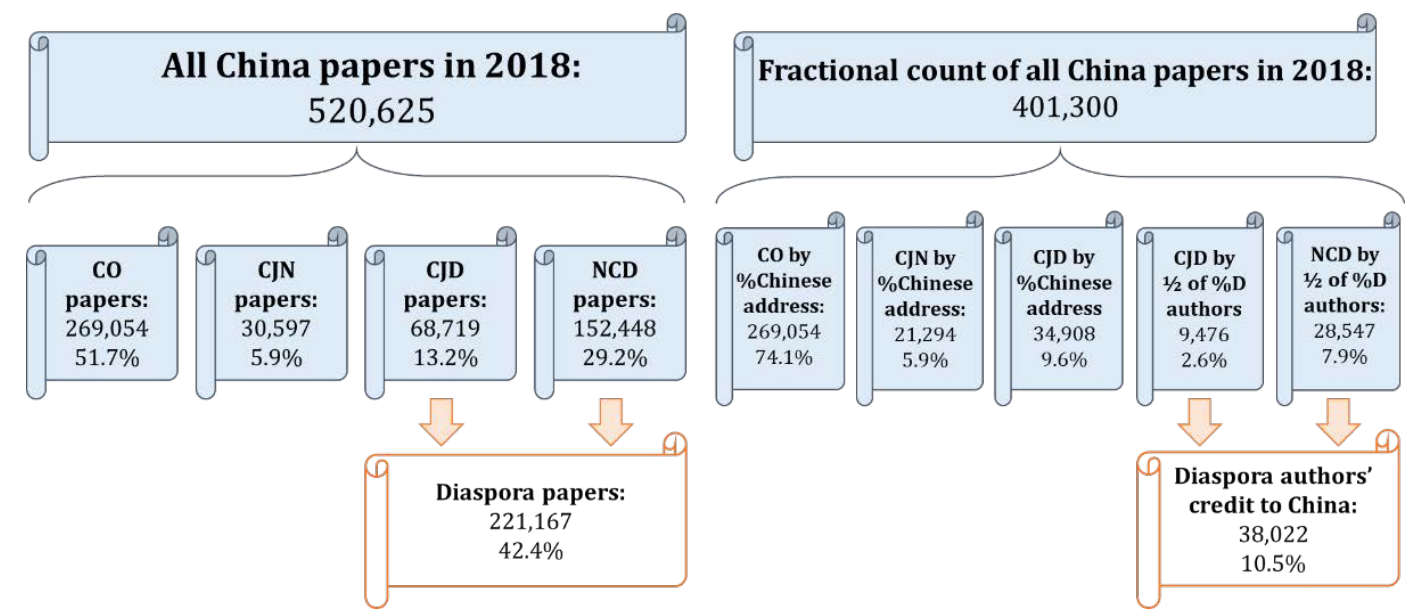

Note: All China papers include papers with at least one China-addressed author or Chinese named 
author, which are the union of CO papers, CJN papers, CJD papers, and NCD papers. By dividing the diaspora fractional counts between the address of their affiliations and Chinese names, we give $1 / 2$ of their credit to their address country (non-China) and the other half to their Chinese name (China).

Source: Scopus database

\subsection{Estimated share of catch-up}

Accepting the view that some portion of diaspora research is part of China's research system writ large, we use the five name-address groups in figures 1 and 2 to measure the proportion of China's increase in papers and citations that came via diaspora research. With citation data that ends in 2015, we measured the change in China's share of global papers and citations, including diaspora research, from 2000 to 2015 and then calculated the proportion of the change in China's share due to the change in diaspora research. Figure 3 assesses the magnitude of the diaspora contribution to China's catch-up in papers and citations, using our maximal "proximity” measure and our minimal fractional count measures. Appendix B gives the details of how we derived each of the estimates.

Figure 3. Estimated Contribution of Diaspora Research to China's Catch-up in World Papers and Citations between 2000 and 2015.

\section{$\checkmark$ By presence By fractional count}

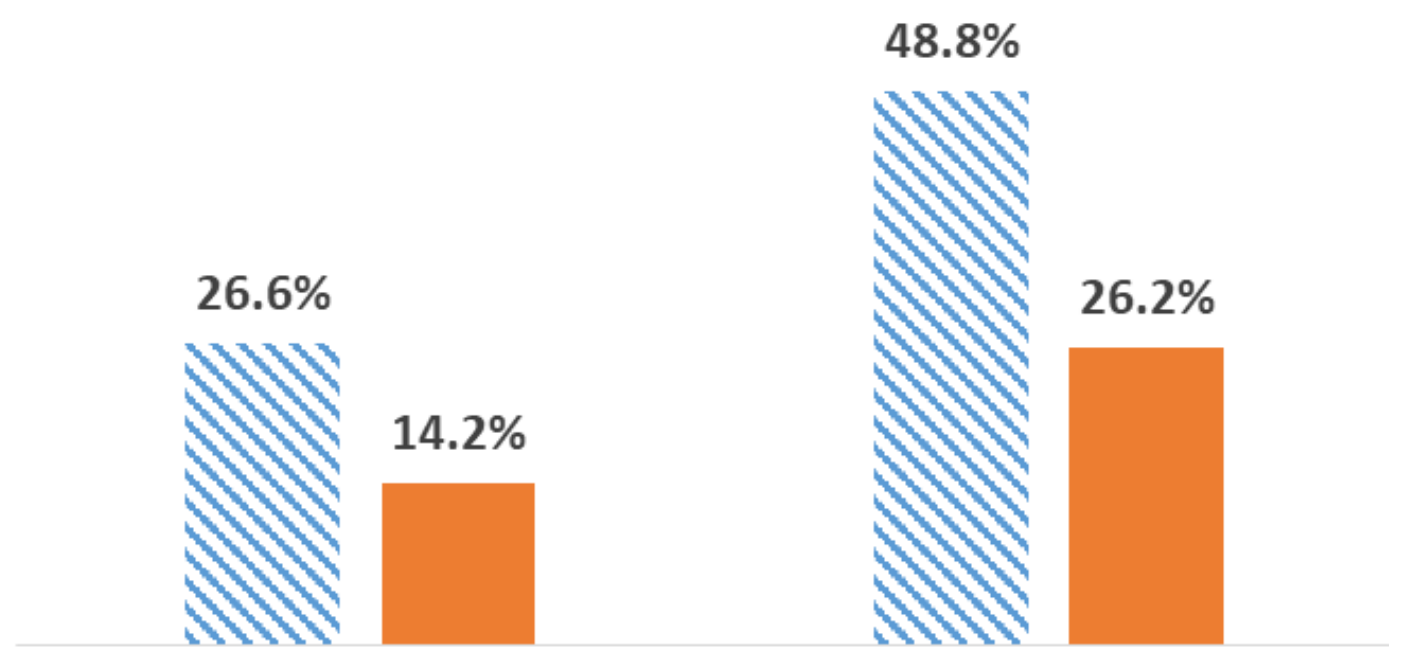

China's catch-up in world papers China's catch-up in world citations 
Note: The Calculations are based on the numbers in Appendix B. The estimated contribution of diaspora research to China's catch-up in world papers by presence is calculated by dividing the changes of China's share of world papers in line b by the changes of diaspora papers' share of world papers in line a; the estimated contribution of diaspora research to China's catch-up in world citations by presence is calculated by dividing the changes of China's share of world citations in line b by the changes of diaspora papers' share of world citations in line a; the estimated contribution of diaspora research to China's catch-up in world papers by fractional count is calculated by dividing the changes of China's credit of world papers in line $\mathrm{d}$ by the changes of China's credit of world papers from diaspora papers in line c; the estimated contribution of diaspora research to China's catch-up in world citations by fractional count is calculated by dividing the changes of China's credit of world citations in line $d$ by the changes of China's credit of world citations from diaspora papers in line c.

\section{Source: Scopus database}

The Figure 3 shows that the diaspora contribution varies substantially between the paper-based and the share-based measures of diaspora impact and between the maximal presence and minimal fractional count measure. Measured by presence on papers, diaspora research accounts for $26.6 \%$ (=4.5\%/17.0\%) of China's catch-up from 2000 to 2015. Measured by the fractional count, diaspora research accounted 14.2\% $(=2.0 \% / 14.2 \%)$ of the catch-up. The reason for the large difference is that the presence measure counts a paper with one diaspora author and $N$ Non-Chinese authors as a full paper while the fractional measure counts a diaspora paper with at most a $1 / 2$ a paper. In the fractional measure the main driver of China's increased contribution is its huge increase in China-Only addressed papers. Turning to citations, the figure shows much higher estimates of the diaspora contribution to the catch-up, with nearly half of the increase in citations attributed to diaspora research using the presence metric and over a quarter of the increase in citations attributed to diaspora research using the fractional count metric. The larger diaspora share of citations than of papers reflects the high quality of diaspora research documented in Tables 1-4.

In sum, the analysis shows that, treating diaspora research as part of China's scientific research system, the diaspora community contributed substantively to China's contribution to global research and to the country's catch-up in scientific research. But is diaspora work so closely linked to China's research to merit inclusion with China- 
based research? The answer rests with the validity of our section two hypotheses about the position of diaspora researchers in the co-authorship and citation networks of scientific research. We show next that diaspora researchers did indeed play an outsized role in both networks and impacted China-addressed papers in ways that suggest that the Figure 3 estimates are likely lower bounds to the diaspora contribution to China's rise in the production of scientific knowledge.

\section{Diaspora Research as Node of co-author network}

At least since Newman (2004) networks of co-authors in scientific publications have been viewed as "small-worlds" in which most researchers work with a few others near them in geographic space or with similar personal attributes while a few researchers connect these groups to research far away in geographic or knowledge spaceper the Watts and Strogatz (1998) small world model. The few create long distance connections that speed the flow of information through the network to local researchers and help them keep pace with worldwide developments. In the case of China, our analysis finds that a large share of long distance co-authorship runs through diaspora authors.

We investigate diaspora research in the co-authorship network in two stages.

First, we document that China and the rest-of-the-world co-authorship are highly separated, with far fewer co-authorship between researchers with China and those with rest-of-the-world addresses than would be found absent huge homophily effects in the selection of co-authors. We demonstrate the separation by comparing the observed distribution of co-authors with China addresses and non-China addresses on papers with a given number of authors with the distribution that would result if research teams formed independent of address in the 2018 Scopus data set.

Our counterfactual of what the distribution would be if researchers formed teams without regard to address is based on the addresses of authors of papers written in 2018. 
Authors who wrote $\mathrm{n}$ papers in the year enter the pool $\mathrm{n}$ times as potential co-authors ${ }^{19}$. We estimate that in 2018 76.8\% of all potential co-authors were NC-addressed, of which 6.0\% were diaspora Chinese, while 23.2\% were Chinese-addressed. Using these statistics, the chance of getting two Chinese addressed authors on a two authored paper would be $(0.23)^{2}=0.054$; the chance of getting two non-China-addressed authors would be $(0.768)^{2}$ $=0.590$; and the chance of getting one China addressed and one non-China addressed coauthors would be 0.356 . The actual proportion of two authored papers with a China addressed and non-China addressed author in 2018 was $1.8 \%{ }^{20}$ - a differential of expected to observed of nearly twenty to one. Geographic homophily in selecting co-authors was so strong that almost all two-authored papers were either all China-addressed or all nonChina addressed.

We made calculations of this form for papers published in 2018 with different numbers of authors and found similarly huge divergences between co-authorship that would result from authors joining together in the absence of geographic homophily and the actual distribution of co-authorship between China and the rest-of-the-world. Table 5 presents our results for papers with five authors, which is the average number of authors on papers in 2018 and thus broadly representative of all papers ${ }^{21}$. Column 1 records the expected proportion of $\mathrm{CO}, \mathrm{CJ}$, and $\mathrm{NC}$ papers on the five-author papers from randomly selecting five authors from our pool of potential co-authors. The likelihood of drawing five people from a group with $\alpha \%$ of the distribution is $\alpha^{5}$ so there is essentially zero chance of getting papers with all of one address group save for the large NCN category. Column 2 shows that the observed proportion on joint collaborative papers is far smaller

\footnotetext{
${ }^{19}$ Appendix A gives details of estimating the number of China-addressed authors, diaspora authors and non-diaspora NC-addressed authors.

${ }^{20}$ Estimated based on 2 authored papers in the samples described in Appendix A.

${ }^{21}$ Based on the samples of 2018 papers described in Appendix A, the observed CO, CJN, CJD, NCD, and NCN shares of all papers are 16.8\%, 1.9\%, 4.3\%, 9.5\%, and 67.5\%, and the observed CO, CJN, CJD, NCD, and NCN shares of five authored papers are 19.8\%, 2.1\%, 3.7\%, 8.6\%, and 65.8\%.
} 
than actual and the proportions writing with persons with the same national address far larger in reality than the expected proportions in column 1.

Table 5. Observed and Expected share of 5-author papers, 2018

\begin{tabular}{|c|c|c|}
\hline & $\begin{array}{c}\text { Expected share of all 5-author } \\
\text { papers }\end{array}$ & $\begin{array}{c}\text { Observed share of all 5-author pa- } \\
\text { pers }\end{array}$ \\
\hline CO & $0.1 \%$ & $19.8 \%$ \\
\hline CJ & $73.2 \%$ & $5.8 \%$ \\
\hline NC & $26.7 \%$ & $74.4 \%$ \\
\hline
\end{tabular}

Note: Expected shares are calculated by proportions of Chinese addressed authors published in 2018: 23.2\% and proportion of non-Chinese addressed authors published in 2018: 76.8\%.

Source: Scopus database.

Viewing China and non-China papers as the product of local networks of researcher slacking co-authors from the other area arguably creates a need for some researchers to provide the long connection that speeds the diffusion of knowledge in an efficient network. Hypothesis H1 that diaspora Chinese researchers play that role in the co-authorship network linking China and the rest-of-the-world suggests that diaspora researchers ought to be found in exceptionally large numbers on CJ papers - far above the numbers that would result if diaspora researchers had the same likelihood of having a Chinese coauthor as NCN authors. Accordingly, the second part of our analysis compares the observed proportion of diaspora authors on China and rest-of-the-world collaborations with the proportion that would arise if the composition of non-China addressed authors was independent of ethnicity.

Table 6 reports the results of this analysis for CJ papers with 1, 2, 3 and 4 or more NC authors on the collaboration. Column 1 shows the distribution of CJ papers by the number of NC authors ${ }^{22}$ Nearly half of the papers (46\%) have only one NC author, $21 \%$ of the papers have 2 NC authors, and $12 \%$ have 3 NC authors, with the remaining 22\% having 4 or more. Column 2 gives the expected share of the CJ

\footnotetext{
${ }^{22}$ In 2018 NC authors made up 43\%, of all the authors on CJ papers, a proportion that has been relatively steady over time.
} 
papers that should have at least one diaspora author in the group of NC-addressed authors absent homophily in co-authorship. For papers with one NC author, this probability would be the $7.8 \%$ of NC authors who are diaspora. For papers with more than one author, we calculate the probability as 1- probability for having all nondiaspora authors $=1-(1-0.078)^{\mathrm{n}}$ where $\mathrm{n}=$ number of non-China addressed authors on the observed papers. Column 3 gives the actual proportion of diaspora authors on the CJ papers. The actual proportion exceeds the expected proportion in every case. Among all CJ papers, over half are CJD compared to a probability that $19 \%$ of the papers would be CJD.

Table 6. Observed and Expected division of $\mathrm{CJ}$ papers by the presence of diaspora authors, 2018

\begin{tabular}{|l|c|c|c|c|}
\hline & $\begin{array}{c}\text { 1. Percent } \\
\text { of papers }\end{array}$ & $\begin{array}{c}\text { 2. Expected share of } \\
\text { CJD papers } \\
\text { (at least one D author) }\end{array}$ & $\begin{array}{c}\text { 3. Observed } \\
\text { share of } \\
\text { CJD papers }\end{array}$ & 4 . Ratio \\
\hline CJ & $100 \%$ & $19.0 \%$ & $52.2 \%$ & 2.75 \\
\hline $\begin{array}{l}\text { CJ with 1 NC ad- } \\
\text { dressed author }\end{array}$ & $46 \%$ & $7.8 \%$ & $55.6 \%$ & 7.13 \\
\hline $\begin{array}{l}\text { CJ with 2 NC ad- } \\
\text { dressed authors }\end{array}$ & $21 \%$ & $15.0 \%$ & $43.4 \%$ & 2.89 \\
\hline $\begin{array}{l}\text { CJ with 3 NC ad- } \\
\text { dressed authors }\end{array}$ & $12 \%$ & $21.6 \%$ & $45.3 \%$ & 2.10 \\
\hline $\begin{array}{l}\text { CJ with more than } \\
\text { 3 NC addressed } \\
\text { authors }\end{array}$ & $22 \%$ & $44.7 \%$ & $56.9 \%$ & 1.27 \\
\hline
\end{tabular}

Note: Expected shares are calculated by proportion of diaspora authors published in 2018 among all NC addressed authors: 7.8\%, and proportion of non-Chinese addressed and non-Chinese named authors published in 2018 among all NC addressed authors: 92.2\%. Expected probability for having at least one diaspora authors on an observed CJ papers $=1$ - probability for having all non-diaspora authors $=1-0.922 \mathrm{n}$ where $\mathrm{n}=$ number of non-China addressed authors on the observed papers. Calculations are based on 1287 sampled CJ papers without joint address authors.

Source: Scopus database.

Some of the diaspora authors on CJD papers had joint China-other country addresses, which would likely make them a key connection in the joint research. In fact, 51.1\% of CJD papers had at least one author with dual addresses - almost all of 
which had a diaspora author as their dual addressed authors. By contrast, only $1.3 \%$ of CJN papers had at least one author with a joint China-other country address. Joint address authors are likely to create a stronger link between the China-based team and the NC-based team than other authors and possibly be the key person linking the research in both countries. Indeed $10.0 \%$ of CJD papers were international collaborations solely because at least one author had both an NC and a China address, collaborating with him or herself, as the case might be. Given that CJD papers make up 70\% of China’s international collaborative papers (CJ), this means 7\% were international collaborations because of the joint addressed author. Finally, we estimated the proportion of diaspora authors who are first authors, which in many fields is the researcher who did the most work on the paper, or corresponding authors, who are also likely to play a particularly important role in the research. Diaspora authors are the first or corresponding authors on 31.2\% of the 2018 CJD papers, and thus presumably critical to those papers.

The greater propensity for diaspora researchers to connect China and non-China addressed papers in the network of co-authors also be seen in terms of the probability that an NC paper with a diaspora author is a collaboration with a China-addressed paper compared to the probability that an NC paper without a diaspora author is a collaboration with a China-addressed author. In 2018 31\% (68,719) of the 220,974 papers with a diaspora author were CJD collaborations with China ${ }^{23}$ whereas just $5.5 \%{ }^{24}(68,168)$ of the $1,234,161$ papers with a non-diaspora NC author were CJN collaborations. Papers with diaspora authors were 5.9 times as likely to have China-

\footnotetext{
${ }^{23}$ Estimated by the ratio of number of CJD papers divided by the number of all diaspora papers (CJD and NCD) $=$ CJD $/(C J D+N C D)=68,719 /(152,255+68,719)=31.1 \%$, see Appendix B for details.

${ }^{24}$ The observed probability of non-diaspora NC-addressed authors collaborating with China-addressed authors is equal to the ratio of number of papers with Chinese-addressed authors and non-diaspora NCaddressed authors divided by the number of all papers with non-diaspora NC-addressed authors = $(\mathrm{CJN}+\mathrm{CJD}$ with non-D authors) $/(\mathrm{CJN}+\mathrm{CJD}$ with non-D authors + NC with non-diaspora authors $)=$ $(30,597+37,566) /(30,597+37,566+1,225,309)=5.3 \%$, see Appendix A for details.
} 
addressed collaborators as papers with non-diaspora NC authors. As a consequence, CJD papers made up a stable $70 \%$ of CJ papers from 2000 to $2018^{25}$.

In sum, diaspora researchers were far more likely than other NC addressed authors to work with China addressed authors, consistent with the ethnic network view of scientists migrating from source to destination country as a conduit of knowledge to the source country rather than as a brain drain loss.

\section{Diaspora research transmitting knowledge through citations}

Diaspora researchers also play an out-sized role in the citation network linking China-addressed papers and non-China-addressed papers. As with co-authorship, there is strong geographic homophily in citations of papers by country (Bakare and Lewison, 2017). In the three year forward citation data that we use, nearly 2/3rds (64.8\%) of the citations received by China-addressed papers published in 2015 came from China-addressed publications in 2016-2018 that constituted 20.3\% of world S\&E publications in those years ${ }^{26}$, producing an over-citing rate of $3.2(=64.8 / 20.3)$. Because all China-addressed papers include CJ papers, where the presence of NC addressed authors should dilute geographic homophily in citations, we also estimated the over-citing ratio of 2016-2018 CO publications to 2015 CO papers ${ }^{27}$. The 2015 CO papers received 58.5\% of their three year forward citations from CO publications in 2016-2018 that constituted 15.9\% of world S\&E publications between 2016 and 2018 but accounted, giving a 3.7 over-citing rate. The larger over-citing rate supports

\footnotetext{
${ }^{25}$ Calculated by samples described in Appendix A.

${ }^{26}$ The 1,554,115 China-addressed publications in S\&E fields with at least one China address between 2016 and 2018 are retrieved from Scopus using the querying string. Dividing that by 7,663,908 publications in S\&E fields in Scopus gives the proportion of China-addressed publications - 20.3\%. We estimate $64.8 \%$ of citations to 2015 China-addressed papers are from China-addressed publications in the following 3 years based on samples described in Appendix A.

${ }^{27}$ The $15.9 \%$ CO publications of all Scopus S\&E publications between 2016 and 2018 are calculated using the querying strings. We estimate $58.5 \%$ of citations to 2015 CO papers are from CO publications in the following 3 years based on samples described in Appendix A.
} 
the notion that homophily is strongest among papers with the more narrowly defined China-only group of authors. ${ }^{28}$

To the extent that Chinese-based researchers are more familiar with non-China addressed papers written by diaspora researchers than papers written by non-diaspora researchers through the ethnic knowledge network, diaspora papers offer a potentially fruitful way for China-addressed researchers to obtain information from outside the country. Many China-based researchers are likely to know diaspora researchers as coauthors on papers and possibly through seminars and conferences involving the diaspora researchers in China. These connections should produce more citations of diaspora research than non-diaspora research per Hypothesis 2 in section 2.

Testing the hypothesis that China-addressed researchers cite diaspora work because of ethnic homophily requires, however, taking account of the high quality of diaspora research, which should itself produce more citations from China-addressed papers. We use a "difference in difference” methodology to adjust for quality differences in papers in which we compare the China addressed citation of diaspora papers relative to non-diaspora papers to the non-China addressed citation of diaspora papers relative to non-diaspora papers. Assuming that both China-addressed and nonChina addressed authors respond similarly to quality, the difference in difference would reflect ethnic homophily in citations due to personal connections.

Per section 2's Hypothesis 3, we further expect that ethnic knowledge network connections will make diaspora researchers more aware of Chinese-based research than other non-China addressed researchers and thus more likely to cite China-Only papers. These citations should benefit NC addressed papers by directing readers

\footnotetext{
${ }^{28}$ In addition to citations captured in Scopus that show over-citation, our earlier work ( Xie and Freeman (2019)) on citations in the China National Knowledge Infrastructure (CNKI), database of scientific journals and other material published in China show that Chinese language papers indexed in CNKI database but not in Scopus cite are twice as likely to cite a non-Chinese language China-addressed paper indexed in Scopus compared to a non-Chinese language non China-addressed paper indexed in Scopus.
} 
outside of China to them and possibly offset the presumed inefficiency of over citing papers produced nearby. ${ }^{29}$ Global attention to the papers may help establish Chinaaddressed researchers, particularly young persons at the beginning of their careers, through invitations to conferences and possible future co-authorship - advancing China's catch-up in science. Here, too, we use a difference in difference methodology to test the hypothesis, comparing the ratio of citations that NCD papers give to Chinaaddressed papers to the citations they give to NCN papers to the analogous ratio that NCN papers give to China-addressed papers relative to NCN papers.

\subsection{China Addressed Citation of Diaspora Research}

To assess whether China addressed papers pay more attention to diaspora research than to non-diaspora research at NC addresses, rows 1 and 2 in Table 7 compare the three year forward citations received by diaspora papers (NCD) and nondiaspora papers published in 2015 from China addressed (CO) papers and non-China addressed (NCN) papers published in 2016-2018. Because, as the table shows, there are many more NCD than CO papers among world publications, the majority of citations in rows 1 and 2 come from NCD papers. But there is a striking difference in the distribution of citations between $\mathrm{CO}$ and NCN papers. CO papers gave on average 2.3 citations to 2015 NCD papers compared to 0.9 citations to 2015 NCN papers- a 2.56 to 1 advantage for diasporapapers. NCN papers also give relatively more citations to NCD papers but by a much lower margin of 1.64 to 1 . On the notion that NCN authors are better connected to authors on other NCN papers, which would give an ethnic homophily boost to those citations, the fact that NCN papers give 1.64 more citations to NCD papers strongly supports the notion that they indeed are of higher quality. Assuming that CO and NCN researchers value the quality of the NCD and NCN papers similarly, the ratio of the differentials $1.56(=2.56 / 1.64)$ is a

\footnotetext{
${ }^{29}$ This presumably improves the quality of papers, or at least, to increase citations. Didegah and Thelwall (2013) report that papers in Nanoscience and Nanotechnology field that cite more international research receive more citations than other papers.
} 
“difference in difference” estimate of the tendency of CO papers to rely more on diaspora work via connections with ethnic Chinese authors compared to the tendency of NCN papers to rely on that work ${ }^{30}$.

Table 7. Three Year Forward Citations from 2016-2018 CO and NCN Papers to Non-China Addressed Papers Published in 2015, by Specified Cited Group

\begin{tabular}{|c|c|c|c|c|}
\hline \multirow{2}{*}{\multicolumn{2}{|c|}{ Cited 2015 Papers }} & \multicolumn{2}{|c|}{$\begin{array}{l}\text { Three year forward Citations From } \\
\text { Citing Group }\end{array}$} & \multirow[b]{2}{*}{ Col.1/Col.2 } \\
\hline & & 1 From $C O$ naners & 2. From NCN & \\
\hline \multirow{2}{*}{$\begin{array}{l}\text { Papers with } \\
\text { non-China } \\
\text { Addresses }\end{array}$} & $\begin{array}{l}\text { 1. NCD papers } \\
\text { (9.1\% of all papers) }\end{array}$ & 2.3 & 10.5 & - \\
\hline & $\begin{array}{l}\text { 2. NCN Papers } \\
\text { (72.2\% of all papers) }\end{array}$ & 0.9 & 6.4 & - \\
\hline \multirow{2}{*}{$\begin{array}{c}\text { Papers with } \\
\text { Joint China } \\
\text { and } \\
\text { non-China } \\
\text { Addresses }\end{array}$} & $\begin{array}{l}\text { 3. CJD papers } \\
\text { (3.4\% of all papers) }\end{array}$ & 5.7 & 5.6 & - \\
\hline & $\begin{array}{c}\text { 4. CJN papers } \\
\text { (1.3\% of all papers) }\end{array}$ & 4.3 & 4.5 & - \\
\hline \multicolumn{2}{|c|}{ Row 1/ Row 2} & 2.56 & 1.64 & 1.56 \\
\hline \multicolumn{2}{|c|}{ Row 3/ Row 4} & 1.33 & 1.24 & 1.07 \\
\hline
\end{tabular}

Note: Citations of 2015 CJD and CJN papers are estimated based on a sample of 2,000 CJ papers. Citations of 2015 NCD and NCN papers are estimated based on a sample of 2,000 NC papers, described in Appendix A.

Source: Scopus database.

Rows 3 and 4 of Table 7 extend analysis to China-joint international (CJ) papers, whose authors have addresses in China and addresses outside China (including some authors with dual addresses). The number of citations to the CJD and CJN papers is considerably greater than the number of citations to NC papers in rows 1 and 2, presumably reflecting geographic homophily between CO papers and CJ papers. Given that CJ papers include China and non-China addressed authors we expect less

\footnotetext{
${ }^{30}$ This does not mean that CO papers cite more NCD than NCD papers. They cite more NCN papers because those papers are far more numerous than NCD papers. The differential is in the number of cites relative to the population of citable papers.
} 
geographic homophily in the citations than in the comparison of CO papers and NCN papers and thus for diaspora researchers to have a smaller impact in attracting citations from CO papers. The results show small differentials in citations favoring CJD papers from both CO and NCN papers that are sufficiently similar to indicate that CO papers do not pay more attention to China joint papers with a diaspora author than China joint papers without a diaspora author.

Finally, we note that if results reported by Bornmann et al. (2012) and Didegah and Thelwall (2013) that citing publications of high impact raises the citations of the city paper, presumably in part because the high impact paper has more valuable information than a low impact paper holds for China the China-addressed papers over-citing diaspora papers may raise their quality and future citations.

\subsection{Diaspora Paper Citation of China Only Addressed papers}

To see if diaspora (NCD) papers provide an important pathway for China Only (CO) research to reach non-China based researchers, we counted the citations NCD papers published in 2016-2018 gave to 2015 CO papers relative to the citations they gave to 2015 NCN papers. For our comparison group we counted the citations that 2016-2018 NCN papers give to the 2015 CO papers and 2015 NCN papers.

Column 1 of Table 8 shows that diaspora papers gave roughly the same number of citations to a CO paper (0.6) as to an NCN paper (0.7), giving a ratio of citations of 0.86 . This contrasts sharply with the pattern of citations that non-diaspora papers give to $\mathrm{CO}$ and NCN papers in column (2). NCN papers cite CO papers much less frequently with a ratio of citations to CO papers to NCN papers of 0.33 . As a result the ratio of the ratios in column (5) shows a massive preference of NCD relative to NCN citing behavior toward CO papers of 2.61. From one perspective this shows that diaspora papers are indeed closer to China-addressed research than other papers at non-China addresses, justifying our name-and-address fractional attribution of some of the diaspora research to China.

Table 8. Three Year Forward Citations received by CO Papers relative to NCN 
papers published in 2015, by Specified Citing Group

\begin{tabular}{|c|c|c|c|c|c|c|}
\hline \multirow{3}{*}{$\begin{array}{c}\text { Cited } \\
2015 \\
\text { Papers }\end{array}$} & \multicolumn{4}{|c|}{ Three year forward Citations From Citing Group } & \multirow{3}{*}{$\begin{array}{l}\text { Col.1/ } \\
\text { Col.2 }\end{array}$} & \multirow{3}{*}{$\begin{array}{l}\text { Col.3/ } \\
\text { Col.4 }\end{array}$} \\
\hline & \multicolumn{2}{|c|}{$\begin{array}{c}\text { Papers with non-China } \\
\text { Addresses }\end{array}$} & \multicolumn{2}{|c|}{$\begin{array}{c}\text { Papers with Joint China and } \\
\text { non-China Addresses }\end{array}$} & & \\
\hline & $\begin{array}{l}\text { 1. From NCD } \\
\text { papers } \\
\text { (9.6\% of all } \\
\text { papers) }\end{array}$ & $\begin{array}{c}\text { 2. From } \\
\text { NCN } \\
\text { papers } \\
\text { (70.1\% of all } \\
\text { papers) }\end{array}$ & $\begin{array}{l}\text { 3. From CJD } \\
\text { papers } \\
\text { (3.0\% of all } \\
\text { papers) }\end{array}$ & $\begin{array}{l}\text { 4. From } \\
\text { CJN papers } \\
\text { (1.4\% of all } \\
\text { papers) }\end{array}$ & & \\
\hline $\begin{array}{c}\text { 1. CO } \\
\text { papers } \\
\text { (13.9\% of } \\
\text { all papers) } \\
\end{array}$ & 0.6 & 2.1 & 0.90 & 0.20 & - & - \\
\hline $\begin{array}{l}\text { 2. NCN } \\
\text { Papers } \\
\text { (72.2\% of } \\
\text { all papers) }\end{array}$ & 0.7 & 6.4 & 0.35 & 0.15 & - & - \\
\hline $\begin{array}{l}\text { Row 1/ } \\
\text { Row } 2\end{array}$ & 0.86 & 0.33 & 2.57 & 1.34 & 2.61 & 1.92 \\
\hline $\begin{array}{l}\text { reference } \\
\text { reference }\end{array}$ & NCD for $c i$ & g CO paper & $\begin{array}{l}2.61 \\
1.92\end{array}$ & & & \\
\hline
\end{tabular}

Note: Citations of 2015 CO papers are estimated based on a sample of 2,000 CO papers. Citations of 2015 NCN papers are estimated based on a sample of 2,000 NC papers, described in Appendix A.

Source: Scopus database.

As in Table 7 we expand the analysis to consider the citing behavior of China joint collaborations with other countries in columns (3) and (4). Here we compare the citing behavior of China joint international collaboration papers that include a diaspora author (CJD) with the joint collaborative papers that have no diaspora author. Both CJD and CJN give more cites to CO papers than to NCN papers but the differential in citing is much greater for CJD papers. As the final column in the panel shows, CO papers receive $4.50(=0.9 / 0.2)$ times more citations from CJD papers than from CJN papers while NCN papers receive $2.34(=0.35 / 0.15)$ times more citations from CJD papers than from CJN papers. The ratio of the differentials is $1.92-$ indicating that joint papers with a diaspora author cite CO papers relative to NCN papers nearly twice as frequently as joint papers without a diaspora author. The 
shrinkage of the diaspora effect on citing CO papers from column (5) to column (6) presumably reflects the greater knowledge that China-addressed authors on a joint article are likely to have regarding $\mathrm{CO}$ work than the non-China addressed authors on an NCN paper. Still, the diaspora effect is large, possibly due to diaspora papers having a larger China-born share of researchers than NCN papers or to diaspora authors having a greater influence on the joint papers as first or corresponding authors ${ }^{31}$.

By giving more citations to China-addressed research, diaspora researchers boost China's research presence outside the country. If NCD papers gave CO papers the same number of citations as NCN papers and if CJD papers gave CO papers the same number of citations as CJN papers, citations to 2015 CO papers would shrink by 21.5\% from papers with addresses outside of China, which would reduce them by 8.8\% overall. Looking at the upward trend in citations of CO paper from 1.4 in 2000 to 9.7 in 2015, we estimate that $17 \%$ came from increased citations from diaspora papers $^{32}$.

In sum, by being a source of information for China-addressed papers of scientific work outside the country and by citing China-addressed papers more than other NC papers, diaspora research helped China's catch-up.

\section{Conclusion}

Standard assessments of country contributions to scientific publications credit a paper to a country based on authors' addresses. Since addresses do not distinguish Chinese born researchers working outside China from other non-China addressed researchers, the contribution of these diaspora researchers has been largely ignored.

\footnotetext{
${ }^{31}$ Based on samples described in Appendix A, we estimate that 78.4\% of authors on a 2018 CJD paper are China born compared to 69.6\% China-born authors on a 2018 CJN paper. China born authors are first or corresponding authors on $91.3 \%$ of 2018 on CJD and $82.9 \%$ of CJN papers. It is also possible that some of the diaspora authors have published papers with a China address and add a citation to their own earlier work or that of colleagues whose work they know well.

${ }^{32}$ Estimated based on samples described in Appendix A.
} 
Using an address-name analysis of authors on non-China addressed papers to identify Chinese diaspora researchers, we find that they contributed hugely to global science in numbers of articles and citations. Diaspora researchers have a presence on $13.8 \%$ of all articles published in 2018 and accounted for 4.7\% of 2018 fractional counted journal articles and for $23.0 \%$ of 2015 global citations.

Using our name-and-address method to credit diaspora scientific output to China's research, we estimate that diaspora papers accounted for one-seventh of China's increased share of world papers and for nearly of a quarter of its increased share of world citations in its catch-up in science from 2000 to 2015. Diaspora papers also had an exceptional role connecting science in China to science in the rest-of-theworld through the network of coauthors and the network of citations. In 2015, a diaspora author was 5.6 times more likely than a non-diaspora author working outside China to collaborate with a China addressed author. Papers with diaspora authors cited China-addressed papers more than did other non-China addressed papers and commensurately were cited more by China-addressed papers, making diaspora work part of China's research activity.

These findings support the ethnic network view of the migration of scientists as benefiting source and destination countries against brain drain fears that the mobility of scientists harms source countries. Since science publications are a common good available to all, it further suggests that fears that migrant scientists "steal ideas” from advanced countries are largely groundless. China in science and the world benefited from open door policies that allowed/encouraged diaspora research.

Ideally, our analysis opens the door to additional research on the diaspora contribution to scientific knowledge that will further illuminate China's catch-up in science and its new place as a leading country in global research. Our focus on scientists working overseas ignored the contribution of diaspora researchers who returned to China, where they contribute to China-addressed papers. Our name-andaddress based accounting framework would benefit from evidence on the weights that 
might best divide credit between China and destination countries. Estimates of the contribution of diaspora researchers in the co-authorship and citation networks to China's catch-up could be enhanced by investigations of the possible spillover effects from these network connections on the future work of China-based co-authors, authors of cited papers, and of those who cited diaspora papers.

Finally, the finding that diaspora researchers play an important role in source as well as destination country science through co-authorship and citation networks could readily be tested in other settings, where institutions and policies could produce similar or different results. 


\section{References}

Abramo, G. and D’Angelo, C. A. (2015), 'The relationship between the number of authors of a publication, its citations and the impact factor of the publishing journal: Evidence from Italy', Journal of Informetrics, 9(4), 746-761.

Abramo, G., Cicero, T., and D’Angelo, C. A. (2011), 'Assessing the varying level of impact measurement accuracy as a function of the citation window length', Journal of Informetrics, 5(4), 659-667.

Abrishami, A. and Aliakbary, S. (2019), 'Predicting citation counts based on deep neural network learning techniques', Journal of Informetrics, 13(2), 485-499.

Agrawal, A., Kapur, D., McHale, J., and Oettl, A. (2011), 'Brain drain or brain bank? The impact of skilled emigration on poor-country innovation', Journal of Urban Economics, 69(1), 43-55.

Aleksynska, M., and Peri, G. (2014), 'Isolating the network effect of immigrants on trade', The World Economy, 37(3), 434-455.

AlShebli, B. K., Rahwan, T., and Woon, W. L. (2018), 'The preeminence of ethnic diversity in scientific collaboration', Nature Communications, 9(1), 1-10.

Aman, V. (2020), 'Transfer of knowledge through international scientific mobility: Introduction of a network-based bibliometric approach to study different knowledge types', Quantitative Science Studies, 1(2), 1-17.

Ambekar, A., Ward, C., Mohammed, J., Male, S., and Skiena, S. (2009), 'Nameethnicity classification from open sources', Proceedings of the 15th ACM SIGKDD international conference on Knowledge Discovery and Data Mining, 49-58.

Bakare, V. and Lewison, G. (2017), 'Country over-citation ratios', Scientometrics, 113(2), 1199-1207.

Behncke, N. (2014), 'The Structure of Ethnic Networks and Exports: Evidence from Germany', CEGE Discussion Paper, No. 198. https://ssrn.com/abstract=2412046 or http://dx.doi.org/10.2139/ssrn.2412046. 
Bohannon, J. and Doran, K. (2017), 'Introducing orcid', Science, 356(63390, 691692.

Börner, K., Contractor, N., Falk-Krzesinski, H. J., Fiore, S. M., Hall, K. L., Keyton, J., ... and Uzzi, B. (2010), 'A multi-level systems perspective for the science of team science', Science Translational Medicine, 2(49), 49cm24-49cm24.

Bornmann, L., Leydesdorff, L., and Wang, J. (2014), 'How to improve the prediction based on citation impact percentiles for years shortly after the publication date?', Journal of Informetrics, 8(1), 175-180.

Bornmann, L. and Daniel, H. D. (2008), 'What do citation counts measure? A review of studies on citing behavior', Journal of documentation, 64, 45-80.

Bornmann, L., Schier, H., Marx, W., and Daniel, H. D. (2012), 'What factors determine citation counts of publications in chemistry besides their quality?', Journal of Informetrics, 6(1), 11-18.

Boschini, A. and Sjögren, A. (2007), 'Is team formation gender neutral? Evidence from coauthorship patterns’, Journal of Labor Economics, 25(2), 325-365.

Cao, C. (2008), 'China's brain drain at the high end: why government policies have failed to attract first-rate academics to return', Asian Population Studies, 4(3), 331345.

Chen, J., Yin, X., Fu, X., and McKern, B. (2020), Beyond Catch-up: Could China Become the Global Innovation Powerhouse? -- China's Innovation Progress, Challenges and Path towards Global Innovation Leadership', Industrial and Corporate Change, forthcoming.

Chen, X. (2009), 'Review on China's Policies for Chinese Students Going Abroad over Last Three Decade’, Journal of Xuzhou Normal University, 35(4), 1-8 (In Chinese language).

Conchi, S. and Michels, C. (2014), 'Scientific mobility: An analysis of Germany, Austria, France and Great Britain', Fraunhofer ISI Discussion Papers- Innovation Systems and Policy Analysis, No. 41.

Czaika, M. and Orazbayev, S. (2018), 'The globalisation of scientific mobility, 19702014’, Applied Geography, 96, 1-10. 
Didegah, F. and Thelwall, M. (2013), 'Determinants of research citation impact in nanoscience and nanotechnology', Journal of the American Society for Information Science and Technology, 64(5), 1055-1064.

Docquier, F., Lohest, O., and Marfouk, A. (2007), 'Brain drain in developing countries', The World Bank Economic Review, 21(2), 193-218.

Docquier, F. and Rapoport, H. (2012), 'Globalization, brain drain, and development', Journal of Economic Literature, 50(3), 681-730.

Felbermayr, G. J., Jung, B., and Toubal, F. (2010), 'Ethnic networks, information, and international trade: Revisiting the evidence', Annals of Economics and Statistics/Annales d'Économie et de Statistique, 41-70.

Freeman, R. B. and Huang, W. (2015), 'Collaborating with people like me: Ethnic coauthorship within the United States', Journal of Labor Economics, 33(S1), S289S318.

Glänzel, W. and Schubert, A. (2005), 'Domesticity and internationality in coauthorship, references and citations’, Scientometrics, 65(3), 323-342.

Ghiasi, G., Mongeon, P., Sugimoto, C., and Larivière, V. (2018), 'Gender homophily in citations', 23rd International Conference on Science and Technology Indicators (STI 2018), September 2018, 1519-1525.

Katz, J. and Hicks, D. (1997), 'How much is a collaboration worth? A calibrated bibliometric model’, Scientometrics, 40(3), 541-554.

Kerr, W. R. (2008), 'Ethnic scientific communities and international technology diffusion', The Review of Economics and Statistics, 90(3), 518-537.

King, M. M., Bergstrom, C. T., Correll, S. J., Jacquet, J., and West, J. D. (2017), 'Men set their own cites high: Gender and self-citation across fields and over time', Socius, 3, 2378023117738903.

Larivière, V., Kiermer, V., MacCallum, C. J., McNutt, M., Patterson, M., Pulverer, B., Swaminathan, S., Taylor, S. and Curry, S. (2016), 'A simple proposal for the publication of journal citation distributions', BioRxiv, 062109.

Lariviere, V. and Sugimoto, C. R. (2019), ‘The journal impact factor: a brief history, 
critique, and discussion of adverse effects', Springer handbook of science and technology indicators, 3-24.

McPherson, M., Smith-Lovin, L., and Cook, J. M. (2001), 'Birds of a feather: Homophily in social networks', Annual review of sociology, 27(1), 415-444.

Miao, D., Wei, Z., Bai, Y., Long, M., and Chen, X. (2009), 'Memorabilia in the 60 Years of China's Oversea Education', World Education Information, 10, 35-40. (In Chinese language)

National Science Board. (2020), Science \& Engineering Indicators 2020, National Science Foundation. https://ncses.nsf.gov/indicators.

Newman, M. E. (2004), 'Coauthorship networks and patterns of scientific collaboration', Proceedings of the national academy of sciences, 101 (suppl 1), 52005205.

Robinson-Garcia, N., Sugimoto, C. R., Murray, D., Yegros-Yegros, A., Larivière, V., and Costas, R. (2019), 'The many faces of mobility: Using bibliometric data to measure the movement of scientists', Journal of Informetrics, 13(1), 50-63.

Felbermayr Saxenian, A. and Hsu, J. (2001), 'The Silicon Valley-Hsinchu Connection: Technical Communities and Industrial Upgrading’, Industrial and Corporate Change, 10(4), 893-920. https://doi.org/10.1093/icc/10.4.893

Saxenian, A. (2002), 'Brain circulation. How high-skill immigration makes everyone better off', Brookings Review, 20(1), 28-31.

Schubert, A. and Glänzel, W. (2006), 'Cross-national preference in co-authorship, references and citations’, Scientometrics, 69(2), 409-428.

Stephan, P. E. and Levin, S. G. (2001), 'Exceptional contributions to US science by the foreign-born and foreign-educated', Population research and Policy review, 20(12), 59-79.

Watts, D. J. and Strogatz, S. H. (1998), 'Collective dynamics of 'small-world' networks', Nature, 393(6684), 440-442.

Wang, J. (2013), 'Citation time window choice for research impact evaluation', Scientometrics, 94(3), 851-872. 
Wang, Y. S., Lee, C. J., West, J. D., Bergstrom, C. T., and Erosheva, E. A. (2019), 'Gender-based homophily in collaborations across a heterogeneous scholarly landscape', arXiv preprint, arXiv:1909.01284.

Xie, Q. and Freeman, R. B. (2019), 'Bigger Than You Thought: China's Contribution to Scientific Publications and Its Impact on the Global Economy', China \& World Economy, 27(1), 1-27.

Yan, E. and Ding, Y. (2012), 'Scholarly network similarities: How bibliographic coupling networks, citation networks, cocitation networks, topical networks, coauthorship networks, and coword networks relate to each other', Journal of the American Society for Information Science and Technology, 63(7), 1313-1326.

Ye, J., Han, S., Hu, Y., Coskun, B., Liu, M., Qin, H., and Skiena, S. (2017, November). Nationality classification using name embeddings. In Proceedings of the 2017 ACM on Conference on Information and Knowledge Management (pp. 18971906).

Ziguras, C. and Gribble, C. (2015), 'Policy responses to address student "brain drain” an assessment of measures intended to reduce the emigration of Singaporean international students', Journal of studies in International Education, 19(3), 246-26. 


\section{Appendix A. The data set of sampled papers and the calculations of diaspora papers}

There are two ways to use data from Scopus in analysis. The first method is to download a file that contains bibliographic data on of papers from the Scopus online website https://www.scopus.com using the Scopus query string ( https://service.elsevier.com/app/answers/detail/a_id/11365/c/10545/

supporthub/scopus/). The second is to make requests to the server of Elsevier and get the response content through its API (Application programming interface).

Downloading files from the first channel does not provide the first names of researchers that we need to differentiate mainland-born persons from citizens or permanent residences born in other countries that meets our definition of diaspora researchers. It also does not give sufficiently detailed data to determine the position of diaspora researchers in the citation network of papers. It records the number of citations a paper receives but little about the citing papers. It also does not report the address or name of authors of the papers in the reference part of a paper.

To extract evidence on those aspects of papers, we undertook a two-part analysis.

First, we randomly selected samples of 2000 articles from the Scopus English journal articles with valid address or name information that are the focus of our study. The query string in Scopus allows 2,000 papers to be downloaded in any query. It reports up to 100 pages of data for each query, with each page containing from 20 to 200 items. We specify the result page to show 100 items per page. To draw the random samples, we generated 20 random numbers between 1 100 from the random function in Excel and used the numbers to select 20 pages with papers for our sample. The 100 papers in each of the 20 pages gives us a sample of 2,000 papers out of the 10,000 items in the query. The downloaded files contain the author name and address information and other bibliographic information - the title of paper, the publication year, and the ISSN number of the journal etc. But they don't report the first names of authors nor which publication in Scopus cites the selected papers.

Second, using the paper identifier in the downloaded files, we added the desired information to the samples through Elsevier API. We find information on the first names of authors and the papers that cited the paper using the unique identifier assigned to papers in Scopus - EID (see:

https://dev.elsevier.com/guides/ScopusSearchViews.htm) and added the first names and the author and address information of the citers of the selected samples via the API portal provided by Elsevier (see: https://dev.elsevier.com/api_docs.html). To get the address and name information of the references in papers in our sample, we accessed the metadata of papers to get the EID code of the references indexed in Scopus through the Elsevier API. We then obtained the detailed address and name information of those cited papers using their EID also through Elsevier API. 
The 2000 paper maximum sample that Scopus allowed for an inquiry gives us an adequate number of observations for generalizing to the larger population of all papers. As most of our statistics are counts that we use to compute proportions of papers in different groups, we calculate the sampling error for estimating a proportion in a random sample of 2,000. It is quite small, with a maximum value on the order of 0.006 for a true proportion of 0.50 . This allows us to distinguish modest differences in shares of the magnitudes we observe with a high level of significance. As noted in the text, in the case where we had a substantially smaller sample with just 324 persons with Chinese last names in the 2018 NC sample from which to calculate the proportion with Chinese first names, we drew a much larger sample of 2,000 NC papers with at least one Chinese last-named author and obtained virtually identical estimates of the proportion with Chinese first names as in the smaller sample.

Table A-1 lists the data samples that we created. Our focus on diaspora authors meant that we sampled papers with diaspora authors more intensely than papers with all China addresses. The number of 2,000 samples for CJ papers is particularly large because we wanted to track the change over time carefully for a related project. The 2018 sample of NC papers with China last named authors was our check on the estimated proportion of China named authors who also had Chinese first names.

Table A-1. Samples used in this analysis

\begin{tabular}{|l|l|c|c|}
\hline \multicolumn{1}{|c|}{ Data Sample } & \multicolumn{1}{c|}{ Purpose } & $\begin{array}{r}\text { Years } \\
\text { Covered }\end{array}$ & $\begin{array}{c}\text { Total number } \\
\text { sampled }\end{array}$ \\
\hline $\begin{array}{l}\text { Papers with only } \\
\text { non-China addresses }\end{array}$ & $\begin{array}{l}\text { Obtain data on largest } \\
\text { group of papers; find those } \\
\text { with China first and last } \\
\text { names. }\end{array}$ & $\begin{array}{c}\text { 2000, } \\
2015, \\
2016-2018\end{array}$ & $\begin{array}{c}2,000 \text { in each year } \\
\text { for total of 10,000 }\end{array}$ \\
\hline $\begin{array}{c}\text { Papers with only } \\
\text { non-China addresses } \\
\text { and China last named } \\
\text { authors }\end{array}$ & $\begin{array}{l}\text { Get larger sample to } \\
\text { estimate the proportion of } \\
\text { NC papers with Chinese } \\
\text { last and first named author } \\
\text { in NC papers with Chinese } \\
\text { last-named author }\end{array}$ & 2018 & 2,000 in year for \\
total of 2,000
\end{tabular}




\begin{tabular}{|l|c|c|c|} 
China Only papers & $\begin{array}{c}\text { Obtain data on largest } \\
\text { group of CO papers }\end{array}$ & $\begin{array}{c}2000, \\
2015,\end{array}$ & $\begin{array}{c}2000 \text { papers in } \\
\text { each year for total } \\
\text { of } 10,000 \text { papers }\end{array}$ \\
\hline
\end{tabular}

Table A-2 records the number of cited and referenced papers we developed from our samples for 2015.

\begin{tabular}{|c|c|c|c|}
\hline Data Sample & $\begin{array}{c}\text { Number } \\
\text { of papers }\end{array}$ & $\begin{array}{c}\text { Number of papers } \\
\text { which cite the } \\
\text { sampled papers } \\
\text { published in 2015 }\end{array}$ & $\begin{array}{c}\text { Number of } \\
\text { referenced papers of } \\
\text { sampled papers } \\
\text { published in 2018 }\end{array}$ \\
\hline $\begin{array}{c}\text { Papers with only } \\
\text { Non-China addresses }\end{array}$ & 2,000 & 19,415 & 70,561 \\
\hline $\begin{array}{c}\text { China Joint papers } \\
\text { with China and other } \\
\text { country addresses }\end{array}$ & 2,000 & 32,324 & 80,433 \\
\hline China only papers & 2,000 & 18,160 & 76,556 \\
\hline
\end{tabular}

Table A-3 describes how we estimate the number of diaspora papers in 2018 and the fractional count of diaspora papers.

Table A-3.

\begin{tabular}{|l|c|c|}
\hline \multicolumn{1}{|c|}{ Definition and Source } & Number & $\begin{array}{c}\text { Relative to } \\
\text { World }\end{array}$ \\
\hline All Journal Articles published in $\mathbf{2 0 1 8}$ & $1,602,030$ & $100 \%$ \\
\hline 1. Papers with China Only address (CO) & 269,054 & $16.8 \%$ \\
\hline $\begin{array}{l}\text { 2. Papers with Only Non-China address (NC) } \\
\text { a) NC Papers with at least one Chinese last-named } \\
\text { author }\end{array}$ & $1,233,660$ & $77.0 \%$ \\
\hline
\end{tabular}


b) NC Diaspora Papers, estimated from 2,000 NC papers and 2,000 NC papers with at least one Chinese last-named author (NCD)

\begin{tabular}{|c|c|c|}
\hline 3. Papers with at least one $C$ and one NC address (CJ) & 99,316 & $6.2 \%$ \\
\hline $\begin{array}{l}\text { a) CJ papers with at least one Chinese last name at NC } \\
\text { address, estimated from 2,000 CJ papers }\end{array}$ & 83,908 & $5.2 \%$ \\
\hline $\begin{array}{l}\text { b) CJ Diaspora papers (CJD), based on \% papers with at } \\
\text { least one Chinese first \& last-named authors at NC address } \\
\text { in 2,000 CJ sample }\end{array}$ & 68,719 & $4.3 \%$ \\
\hline \multicolumn{3}{|l|}{$\begin{array}{l}\text { 4. Papers with Chinese names and Non-China } \\
\text { Addresses }\end{array}$} \\
\hline $\begin{array}{l}\text { a) NC Papers with at least one Chinese last-named } \\
\text { author, } 2 a+3 a\end{array}$ & 274,948 & $17.2 \%$ \\
\hline $\begin{array}{l}\text { b) NC papers with at least Chinese first and last-named } \\
\text { author, } 2 b+3 b\end{array}$ & 220,974 & $13.8 \%$ \\
\hline \multicolumn{3}{|l|}{$\begin{array}{l}\text { 5. Fractional Counts of diaspora papers by Treating } \\
\text { Diaspora as Separate Country }\end{array}$} \\
\hline $\begin{array}{l}\text { a) Fractional Count NC Diaspora Papers, based on } \\
\text { 37.5\% share of China names on papers from 2,000 NC } \\
\text { sample * line } 2 b\end{array}$ & 57,093 & $3.6 \%$ \\
\hline $\begin{array}{l}\text { b) Fractional Count CJD papers based on } 27.6 \% \\
\text { estimated Chinese names on NC address from 2,000 CJ } \\
\text { sample x line } 3 \mathrm{~b}\end{array}$ & 18,951 & $1.2 \%$ \\
\hline c) Fractional Count of all Diaspora Papers $(5 a+5 b)$ & 76,044 & $4.7 \%$ \\
\hline
\end{tabular}

Note: China number of papers fractionated by giving China a proportion of each CJ paper dependent on \% of authors with China address, with China credited for authors with a $\mathrm{C}$ and one or more NC addresses, proportion to China's share of addresses. Base on the same samples, we estimate the percent of CJD papers with at least one non-diaspora NC-addressed author is 54.7\%, and calculate the number of CJD papers with at least one non-diaspora NC-addressed author $=$ $68,719 * 54.7 \%=37,566$. Similarly, we estimate the percent of NCD papers with at least one nondiaspora author is $94.5 \%$, and calculate the number of NCD papers with at least one non-diaspora authors $=152,255 * 94.5 \%=144,087$ 
Tables A-4 and A-5 describes how we estimate the number of China-addressed authors, diaspora authors and non-diaspora NC-addressed authors on 2018 papers.

Table A-4.

\begin{tabular}{|c|c|c|c|c|c|c|}
\hline & $\begin{array}{c}\text { Average number } \\
\text { of authors per pa- } \\
\text { per }\end{array}$ & \#papers & \#authors & $\begin{array}{c}\text { \%China-ad- } \\
\text { dressed authors }\end{array}$ & $\begin{array}{c}\text { \%diaspora au- } \\
\text { thors }\end{array}$ & \%NCN authors \\
\hline CO & 6.2 & 269,054 & $1,659,794$ & $100.0 \%$ & $0.0 \%$ & $0.0 \%$ \\
\hline CJN & 7.4 & 30,597 & 227,295 & $69.6 \%$ & $0.0 \%$ & $30.4 \%$ \\
\hline CJD & 8.9 & 68,719 & 611,234 & $50.8 \%$ & $27.6 \%$ & $21.6 \%$ \\
\hline NCD & 6.5 & 152,255 & 996,147 & $0.0 \%$ & $37.5 \%$ & $62.5 \%$ \\
\hline NCN & 5.2 & $1,081,405$ & $5,667,016$ & $0.0 \%$ & $0.0 \%$ & $100.0 \%$ \\
\hline
\end{tabular}

Note: We calculate the number of total authors on each types of papers in column 3 by multiplying the average number of authors per paper in column 1 with number of papers in column 2. The average number of authors per paper in column 1 are estimate based on samples described in Table A-1. If on authors appear on 4 papers published in 2018, this author will be counted 4 times.

Table A-5. China-addressed authors, diaspora authors and non-diaspora NC-addressed authors on types of papers

\begin{tabular}{|c|c|c|c|}
\hline & China-addressed authors & diaspora authors & NCN authors \\
\hline CO & $1,659,794$ & 0 & 0 \\
\hline CJN & 158,189 & 0 & 69,106 \\
\hline CJD & 310,495 & 168,564 & 132,176 \\
\hline NCD & 0 & 373,541 & 622,606 \\
\hline NCN & 0 & 0 & $5,667,016$ \\
\hline Sum & $\mathbf{2 , 1 2 8 , 4 7 8}$ & $\mathbf{5 4 2 , 1 0 5}$ & $\mathbf{6 , 4 9 0 , 9 0 3}$ \\
\hline Percent & $\mathbf{2 3 . 2 \%}$ & $\mathbf{6 . 0} \%$ & $\mathbf{7 0 . 8 \%}$ \\
\hline
\end{tabular}

Note: Number of types of authors are calculated by multiplying the proportion of authors shown in columns 4-6 of Table A-4 with the number of total authors shown in columns 3 of Table A-4. 
Appendix B. China's share of papers and citations in 2000 and 2015 by presence and fractional counts.

\begin{tabular}{|c|c|c|c|c|c|c|}
\hline & \multicolumn{3}{|c|}{ \#Papers } & \multicolumn{3}{|c|}{ \#Citations } \\
\hline & 2000 & 2015 & Change & 2000 & 2015 & Change \\
\hline \multirow[t]{2}{*}{ World } & 733,757 & $1,460,120$ & 726,363 & $5,338,694$ & $14,360,449$ & $9,021,754$ \\
\hline & \multicolumn{3}{|c|}{ Share of world papers by China presence } & \multicolumn{3}{|c|}{ Share of world citations by China presence } \\
\hline 1. $\mathrm{CO}$ & \multirow{4}{*}{$\begin{array}{l}2.4 \% \\
7.4 \% \\
0.6 \% \\
0.3 \% \\
\end{array}$} & \multirow{4}{*}{$\begin{array}{c}13.9 \% \\
9.1 \% \\
3.4 \% \\
1.3 \% \\
\end{array}$} & \multirow{4}{*}{$\begin{array}{c}11.5 \% \\
1.7 \% \\
2.8 \% \\
1.0 \%\end{array}$} & \multirow{4}{*}{$\begin{array}{l}0.5 \% \\
9.3 \% \\
0.5 \% \\
0.2 \% \\
\end{array}$} & \multirow{4}{*}{$\begin{array}{c}12.9 \% \\
17.0 \% \\
6.1 \% \\
1.6 \% \\
\end{array}$} & $12.4 \%$ \\
\hline 2. $N C D$ & & & & & & $7.7 \%$ \\
\hline 3. CJD & & & & & & $5.6 \%$ \\
\hline \multirow[t]{2}{*}{ 4. CJN } & & & & & & $1.5 \%$ \\
\hline & \multicolumn{3}{|c|}{ Share of fractional count of world papers } & \multicolumn{3}{|c|}{ Share of fractional count of world citations } \\
\hline 5. CO (China authors and address) & \multirow{3}{*}{$\begin{array}{l}2.4 \% \\
0.2 \% \\
0.1 \%\end{array}$} & \multirow{3}{*}{$\begin{array}{c}13.9 \% \\
1.6 \% \\
0.5 \%\end{array}$} & \multirow{3}{*}{$\begin{array}{c}11.5 \% \\
1.4 \% \\
0.4 \%\end{array}$} & \multirow{3}{*}{$\begin{array}{l}0.5 \% \\
0.2 \% \\
0.1 \%\end{array}$} & \multirow{2}{*}{$\begin{array}{l}12.9 \% \\
2.9 \%\end{array}$} & \multirow{2}{*}{$\begin{array}{c}12.4 \% \\
2.7 \%\end{array}$} \\
\hline 6. CJD (China authors and address) & & & & & & \\
\hline $\begin{array}{l}\text { 7. CJD (1/2 China authors and NC ad- } \\
\text { dress) }\end{array}$ & & & & & $0.8 \%$ & $0.8 \%$ \\
\hline $\begin{array}{l}\text { 8. NCD (1/2 China authors and NC ad- } \\
\text { dress) }\end{array}$ & \multirow{2}{*}{$\begin{array}{l}1.3 \% \\
0.2 \% \\
\end{array}$} & \multirow{2}{*}{$\begin{array}{l}1.6 \% \\
0.8 \% \\
\end{array}$} & \multirow{2}{*}{$\begin{array}{l}0.2 \% \\
0.6 \% \\
\end{array}$} & \multirow{2}{*}{$\begin{array}{l}1.7 \% \\
0.1 \% \\
\end{array}$} & \multirow{2}{*}{$\begin{array}{l}2.9 \% \\
1.0 \% \\
\end{array}$} & $1.3 \%$ \\
\hline 9. CJN (China authors and address) & & & & & & $0.9 \%$ \\
\hline \multicolumn{7}{|c|}{ China's share of world papers and citations by presence } \\
\hline a. Diaspora papers $(2+3)$ & \multirow{2}{*}{$\begin{array}{c}8.0 \% \\
10.8 \%\end{array}$} & \multirow{2}{*}{$\begin{array}{l}12.5 \% \\
27.8 \%\end{array}$} & \multirow{2}{*}{$\begin{array}{c}4.5 \% \\
17.0 \% \\
\end{array}$} & \multirow{2}{*}{$\begin{array}{c}9.8 \% \\
10.5 \%\end{array}$} & \multirow{2}{*}{$\begin{array}{l}23.0 \% \\
37.6 \%\end{array}$} & \multirow{2}{*}{$\begin{array}{l}13.2 \% \\
27.1 \%\end{array}$} \\
\hline $\begin{array}{l}\text { b. All papers with China presence } \\
(1+2+3+4)\end{array}$ & & & & & & \\
\hline \multicolumn{7}{|c|}{ China's share of world papers and citations by fractional count } \\
\hline $\begin{array}{l}\text { c. Credit to China from diaspora papers } \\
(6+7+8)\end{array}$ & $1.7 \%$ & $3.7 \%$ & $2.0 \%$ & $2.0 \%$ & $6.7 \%$ & $4.7 \%$ \\
\hline
\end{tabular}




\begin{tabular}{l}
\hline \hline d. All credit to China $(5+6+7+8+9)$ \\
Note: The number of citations are calculated by multiplying the number of papers with the means of 3 year forward citations of corresponding type of
\end{tabular}
papers. The means of 3 year forward citations of 2015 papers are shown in Table 1 . In 2000, the means of 3 year forward citations are 9.2 for NCD papers, 5.7 for CJD papers, 4.1 for CJN papers, 1.4 for CO papers, and 7.3 for NCN papers. The proportion of changes of diaspora papers in the changes of number of all China papers between 2000 and $2015=4.5 \% / 17.0 \%=26.6 \%$, and the proportion of changes of citations of diaspora papers in the changes of citations of all China papers between 2000 and $2015=13.2 \% / 27.1 \%=48.8 \%$.

By dividing the diaspora fractional counts between the address of their affiliations and Chinese names, we give $1 / 2$ of their credit to their address country (non-China) and the other half to their Chinese name (China). The proportion of changes of diaspora fractional credit in the changes of fractional numbers of all China papers between 2000 and $2015=0.6 \% / 14.2 \%=4.4 \%$, and the proportion of changes of diaspora fractional citation credit in the changes of fractional citations of all China papers between 2000 and $2015=2.0 \% / 18.1 \%=11.2 \%$. We use the same name and address based country contribution measure to calculate the credit to non-China, which is available on the request from authors.

Numbers in line 1 = the proportion of China-addressed authors * number of CO papers, numbers in line 2 = the proportion of China-addressed authors * number of CJN papers, numbers in line $3=$ the proportion of China-addressed authors * number of CJD papers, numbers in line $4=1 / 2 *$ the proportion of diaspora authors * number of CJD papers, and numbers in line $5=1 / 2 *$ the proportion of diaspora authors * number of NCD papers.

The alternative way of calculating the line $\mathrm{c}$ is only count the lines 7 and 8 in, which imply that the diaspora authors only contribute to their writing part of the CJD papers and have nothing to do with connecting China and NC and forming the CJD papers. But the ethnic network view opposes this assumption. The analysis in the Table 5 shows that this is an incorrect assumption.

Source: Scopus database.

\section{Appendix Table C: Regression Estimates and Standard Errors Relating 3 Year Forward Citations and Cite Scores of 2015 Papers to Groups of Paper Authors, with Field Variables and Number of Authors}

\begin{tabular}{|c|c|c|c|c|c|c|}
\hline Dependent Variable/Group & Citations & Citations & LN(Citations) & LN(Citations) & CiteScores & CiteScores \\
\hline NCD (Diaspora Papers in NC & 10.72 & 9.44 & 0.53 & 0.38 & 1.92 & 1.42 \\
addressed group) & $(1.319)$ & $(1.394)$ & $(0.062)$ & $(0.062)$ & $(0.173)$ & $(0.160)$ \\
\hline CJD (Diaspora Papers in CJ & 10.19 & 8.55 & 0.61 & 0.40 & 1.84 & 1.58 \\
group) & $(0.864)$ & $(0.935)$ & $(0.041)$ & $(0.043)$ & $(0.113)$ & $(0.107)$ \\
\hline CJN (Papers without Diaspora & 4.15 & 3.88 & 0.34 & 0.19 & 0.85 & 0.94 \\
authors in CJ) & $(1.262)$ & $(1.348)$ & $(0.059)$ & $(0.060)$ & $(0.166)$ & $(0.155)$ \\
\hline CO (China Only papers) & 1.16 & 1.24 & 0.11 & 0.06 & -0.08 & -0.15 \\
$(0.779)$ & $(0.852)$ & $(0.037)$ & $(0.039)$ & $(0.103)$ & $(0.098)$ \\
\hline
\end{tabular}




\begin{tabular}{|c|c|c|c|c|c|c|}
\hline $\begin{array}{c}\text { NCN (Papers with no China } \\
\text { address and no diaspora }\end{array}$ & - & - & - & & - & - \\
\hline \multicolumn{7}{|l|}{ Other Factors } \\
\hline 21 Field & no & yes & No & yes & no & yes \\
\hline \#Authors & - & $\begin{array}{c}0.27 \\
(0.035)\end{array}$ & - & $\begin{array}{c}0.42 \\
(0.027)\end{array}$ & - & $\begin{array}{c}0.03 \\
(0.004)\end{array}$ \\
\hline Adj R-squared & 0.0333 & 0.0634 & 0.0525 & 0.1492 & 0.0787 & 0.2293 \\
\hline NOB & 5318 & 5318 & 4874 & 4874 & 5318 & 5318 \\
\hline
\end{tabular}

Note: NCD is the dummy variable of NCD papers; CJD is the dummy variable of CJD papers; CJN is the dummy variable of CJN papers; CO is the dummy variable of CO papers; NCN is the dummy variable of NCN papers and also is our benchmark. Cite Score value is assigned to a paper based on the 2017 cite score value of the journal it published on. The 21 fields are: Multidisciplinary; Agricultural and Biological Sciences; Biochemistry, Genetics and Molecular Biology; Chemical Engineering; Chemistry; Computer Science; Earth and Planetary Sciences; Energy; Engineering; Environmental Science; Immunology and Microbiology; Materials Science; Mathematics; Medicine; Neuroscience; Nursing; Pharmacology, Toxicology and Pharmaceutics; Physics and Astronomy; Veterinary; Dentistry; Health Professions. In the regression of LN citations, the observations with 0 citation are omitted, the results hold up in other function forms as described in footnote 18.

Source: Tabulated from a sample of 2,000 CO papers, a sample of 2,000 CJ papers, and a sample of 2,000 NC papers published in 2015. Observations without valid address or name information are omitted, papers are also omitted if the journals they published on haven't been assigned a 2017 version of cite scores by Scopus, mainly because those journals are newly established. The number of observations for each group are NCD: 364; CJD: 1269; CJN: 401; CO: 1838; NCN: 1446.

All of the codes and the computer prints for the analysis on request from the authors. 